\title{
BIOCIDAL POTENTIALS OF STEM BARK EXTRACTS OF PSIDIUM GUAJAVA (LINN.) ON PANEL OF BACTERIAL STRAINS ASSOCIATED WITH DIARRHEA AND DYSENTERY
}

\author{
OLADAYO RASHEEDAT ABIDOYE ${ }^{1}$, DAVID AYINDE AKINPELU ${ }^{1,2}$, KAZEEM ADEKUNLE ALAYANDE $^{3}$ \\ MAYOWA OLADELE AGUNBIADE ${ }^{2 *}$
}

${ }^{1}$ Department of Microbiology, Obafemi Awolowo University, Ile-Ife, Osun, Nigeria. ${ }^{2}$ Biocatalysis and Technical Biology Research Group, Cape Peninsula University of Technology, Cape Town, South Africa. ${ }^{3}$ Department of Microbiology, North-West University, Mmabatho, Mafikeng, South Africa. Email: mayorlala@gmail.com

Received: 09 October 2019, Revised and Accepted: 17 December 2019

\section{ABSTRACT}

Objective: Investigations were carried out on cidal effects of crude extract and fractions obtained from stem bark of Psidium guajava against a panel of 74 strains of Escherichia coli and Shigella dysenteriae implicated in diarrhea and dysentery infections.

Methods: Powdered sample of the stem bark was extracted in methanol/distilled water (3:2) and then partitioned into different organic solvents. The fractions obtained were subjected to antibacterial tests against a panel of bacterial strains. The minimum inhibitory concentrations (MIC) and minimum bactericidal concentrations (MBC) were determined using agar dilution method while the mode of action of the active fractions was investigated through time-kill dynamics and leakages of proteins and potassium ions from the cells.

Results: All partitioned fractions except the aqueous fraction exhibited antibacterial activities against the panel of bacterial strains at a final concentration of $10 \mathrm{mg} / \mathrm{mL}$. The MIC exhibited by the crude extract against susceptible bacterial strains ranged between $1.56 \mathrm{mg} / \mathrm{mL}$ and $12.5 \mathrm{mg} / \mathrm{mL}$, while the MIC for the four fractions ranged between $0.31 \mathrm{mg} / \mathrm{mL}$ and $5.0 \mathrm{mg} / \mathrm{mL}$. The MBC ranged between 3.13-12.5 mg/mL and 0.63-5.0 mg/mL for the crude extract and fractions, respectively. The time-kill assay revealed that the percentage of the cells killed increase with an increase in the concentrations of the fractions as well as contact time intervals. Proteins and potassium ions leakages from the bacterial cells followed the same trend with that of time-kill assay.

Conclusion: The stem bark extracts of P. guajava exhibited appreciable bactericidal effects on bacterial strains associated with diarrhea and dysentery in humans.

Keywords: Psidium guajava, Antibacterial, Phytochemicals, Killing rate, Protein leakage, Potassium ions leakage.

(c) 2020 The Authors. Published by Innovare Academic Sciences Pvt Ltd. This is an open access article under the CC BY license (http://creativecommons. org/licenses/by/4. 0/) DOI: http://dx.doi.org/10.22159/ajpcr.2020.v13i2.36003

\section{INTRODUCTION}

Medicinal plants serve as a source of folklore remedies for many ailments, especially among the rural dwellers in Africa and many parts of the countries worldwide. Herbal medicines are gradually becoming an integral part of primary health-care delivery. Diarrhea is a very common disease condition in most tropical communities, and the use of herbal decoction is a common practice in its management [1]. Escherichia coli and Shigella dysenteriae are the causative agents of diarrhea and dysentery, respectively. Diarrhea and dysentery are known to be killer diseases especially among the children $[2,3]$. These vectors are now gradually developing resistant against the available antibiotics used as therapy against infections caused by these pathogens. There is an urgent need to source for other potent antimicrobials especially of natural origin to combat infections caused by these pathogens and other microorganisms as well. This will ensure a reduction in the rate of untimely death among the children. This study thus investigated the potency of Psidium guajava stem bark extract against E. coli and S. dysenteriae.

P. guajava is among the widely used medicinal plant in local folklore remedy. Its fruits and leaves have been studied for different medicinal values [4]. P. guajava belongs to the family Myricaceae and comprises 150 species. It is called apple of tropics in English and known as "Guofa" in Yoruba language. P. guajava is a large dicotyledonous shrub and is generally $3-10 \mathrm{~m}$ high with many branches. This tree is characterized by very thin skin and the fruit is ovoid or pear-shaped berry of about 4-12 cm long [5]. P. guajava is valued as a potential source of pectin, ascorbic acid, sugars, and minerals [6]. The main phytochemical constituents of $P$. guajava are tannins, phenolic compounds, flavonoids, sesquiterpene alcohols, and triterpenoid acids [7]. All parts of P. guajava including fruits, leaves, stem, bark, and roots have been used for treating stomach ache and diarrhea in many countries [8] and has been found to possess anticancer properties [9]. The seeds of $P$. guajava are used for the treatment of gastrointestinal infections and are known to possess anti-carcinogenic activity $[10,11]$. The in vitro studies of $P$. guajava leaves and stem bark revealed that they exhibited significant antimicrobial activities against Staphylococcus aureus, S. dysenteriae, Bacillus subtilis, E. coli, Pseudomonas aeruginosa, and Candida albicans [12]. The stem bark extract of P. guajava is an astringent and can be used to treat diarrhea in children, while the flowers have been used to treat bronchitis and eyesores [13]. Han et al. [14] studied the effects of extract from P. guajava on atopic dermatitis and found it to inhibit the chemokine expression in keratinocytes [15]. The extracts from these plants have also been found to be useful in wound healing due to the presence of tannins and flavonoids in P. guajava.

\section{METHODS}

Preparation of microorganisms used for this study

Various stool samples isolates used for this study were E. coli and S. dysenteriae, which were graciously donated by Department of Medical Microbiology and Parasitology, Obafemi Awolowo University, Ile-Ife, Nigeria. The typed cultures of the National Collection of Industrial Bacteria (NCIB) and American Type Culture Collection (ATCC) were collected from the culture collection of Prof D.A. Akinpelu, Department 
Table 1: Susceptibility patterns exhibited by the crude stem bark extract of Psidium guajava and the standard antibiotics against susceptible bacterial isolates

\begin{tabular}{|c|c|c|c|}
\hline \multicolumn{4}{|c|}{ Zones of inhibition (mm)* } \\
\hline $\begin{array}{l}\text { Bacterial } \\
\text { isolates }\end{array}$ & $\begin{array}{l}\text { Psidium guajava } \\
(25 \mathrm{mg} / \mathrm{ml})\end{array}$ & $\begin{array}{l}\text { Streptomycin } \\
(1 \mathrm{mg} / \mathrm{ml})\end{array}$ & $\begin{array}{l}\text { Ampicillin } \\
(1 \mathrm{mg} / \mathrm{ml})\end{array}$ \\
\hline EC1 & $24 \pm 2.00$ & $21 \pm 5.03$ & $10 \pm 1.15$ \\
\hline EC2 & $24 \pm 1.13$ & $22 \pm 4.00$ & 0 \\
\hline EC3 & $25 \pm 1.15$ & $17 \pm 4.16$ & $11 \pm 1.14$ \\
\hline EC4 & $23 \pm 1.14$ & $19 \pm 5.77$ & 0 \\
\hline EC5 & $23 \pm 1.12$ & $20 \pm 4.00$ & 0 \\
\hline EC6 & $27 \pm 1.11$ & $19 \pm 7.02$ & 0 \\
\hline EC7 & $23 \pm 2.31$ & $18 \pm 3.46$ & 0 \\
\hline EC8 & $25 \pm 1.14$ & $21 \pm 6.42$ & 0 \\
\hline EC9 & $25 \pm 1.16$ & $23 \pm 4.61$ & $10 \pm 1.13$ \\
\hline EC10 & $25 \pm 1.15$ & $29 \pm 1.15$ & $12 \pm 2.00$ \\
\hline EC11 & $22 \pm 2.00$ & $28 \pm 2.00$ & $13 \pm 1.12$ \\
\hline EC12 & $24 \pm 2.00$ & $25 \pm 5.03$ & $13 \pm 1.15$ \\
\hline EC13 & $27 \pm 1.14$ & $20 \pm 7.21$ & 0 \\
\hline EC14 & $25 \pm 1.13$ & $26 \pm 4.00$ & $12 \pm 2.00$ \\
\hline EC15 & $27 \pm 1.12$ & $24 \pm 6.92$ & $11 \pm 1.14$ \\
\hline EC16 & $27 \pm 1.15$ & $20 \pm 8.00$ & $11 \pm 1.16$ \\
\hline EC17 & $26 \pm 2.00$ & $21 \pm 4.16$ & 0 \\
\hline EC18 & $26 \pm 2.00$ & $26 \pm 5.29$ & $11 \pm 2.31$ \\
\hline EC19 & $25 \pm 1.15$ & $27 \pm 4.16$ & $13 \pm 1.13$ \\
\hline EC20 & $26 \pm 2.00$ & $21 \pm 5.77$ & $12 \pm 2.00$ \\
\hline EC21 & $25 \pm 1.14$ & $19 \pm 7.02$ & $11 \pm 1.15$ \\
\hline EC22 & $22 \pm 2.00$ & $22 \pm 9.16$ & $13 \pm 1.16$ \\
\hline EC23 & $25 \pm 1.12$ & $25 \pm 5.03$ & $12 \pm 2.00$ \\
\hline EC24 & $25 \pm 1.13$ & $22 \pm 7.21$ & $11 \pm 1.13$ \\
\hline EC25 & $23 \pm 1.15$ & $22 \pm 6.00$ & 0 \\
\hline EC26 & $17 \pm 3.05$ & $18 \pm 2.00$ & 0 \\
\hline EC27 & $25 \pm 2.31$ & $21 \pm 7.02$ & 0 \\
\hline EC28 & $23 \pm 1.15$ & $18 \pm 5.29$ & 0 \\
\hline EC29 & $22 \pm 2.00$ & $19 \pm 9.23$ & $11 \pm 1.16$ \\
\hline EC30 & $23 \pm 3.05$ & $13 \pm 1.15$ & 0 \\
\hline EC31 & $21 \pm 1.14$ & $13 \pm 1.16$ & 0 \\
\hline EC32 & $23 \pm 1.16$ & $16 \pm 4.00$ & 0 \\
\hline EC33 & $24 \pm 2.00$ & $16 \pm 2.00$ & 0 \\
\hline EC34 & $23 \pm 3.05$ & $23 \pm 5.77$ & 0 \\
\hline EC35 & $23 \pm 1.15$ & $23 \pm 7.57$ & 0 \\
\hline EC36 & $20 \pm 2.00$ & $21 \pm 9.01$ & 0 \\
\hline EC37 & $22 \pm 2.00$ & $25 \pm 4.16$ & 0 \\
\hline EC38 & $19 \pm 1.13$ & $16 \pm 5.29$ & 0 \\
\hline EC39 & $23 \pm 2.31$ & $20 \pm 3.46$ & 0 \\
\hline EC40 & $23 \pm 1.15$ & $17 \pm 4.61$ & $10 \pm 1.15$ \\
\hline EC41 & $22 \pm 2.00$ & $16 \pm 3.46$ & 0 \\
\hline EC42 & $22 \pm 2.00$ & $15 \pm 3.05$ & 0 \\
\hline EC43 & $22 \pm 2.00$ & $13 \pm 2.31$ & 0 \\
\hline EC44 & $24 \pm 2.00$ & 0 & 0 \\
\hline EC45 & $21 \pm 1.15$ & 0 & 0 \\
\hline EC46 & $22 \pm 1.14$ & $18 \pm 6.00$ & 0 \\
\hline EC47 & $21 \pm 2.00$ & $13 \pm 1.15$ & 0 \\
\hline EC48 & $22 \pm 2.00$ & 0 & 0 \\
\hline EC49 & $21 \pm 1.15$ & $12 \pm 1.16$ & 0 \\
\hline EC50 & $25 \pm 1.16$ & $21 \pm 4.16$ & $11 \pm 1.15$ \\
\hline EC51 & $22 \pm 1.14$ & $25 \pm 3.05$ & 0 \\
\hline EC52 & $24 \pm 1.16$ & $23 \pm 1.16$ & 0 \\
\hline SH1 & $21 \pm 1.15$ & $18 \pm 2.00$ & 0 \\
\hline $\mathrm{SH} 2$ & $23 \pm 1.16$ & $20 \pm 2.00$ & 0 \\
\hline SH3 & $22 \pm 2.00$ & 0 & 0 \\
\hline SH4 & $23 \pm 1.15$ & 0 & 0 \\
\hline SH5 & $21 \pm 1.14$ & $22 \pm 2.00$ & $11 \pm 1.15$ \\
\hline SH6 & $21 \pm 1.17$ & $21 \pm 1.15$ & 0 \\
\hline SH7 & $22 \pm 2.00$ & 0 & 0 \\
\hline SH8 & $24 \pm 2.00$ & $23 \pm 1.16$ & 0 \\
\hline SH9 & $20 \pm 2.00$ & 0 & 0 \\
\hline SH10 & $24 \pm 2.00$ & $27 \pm 3.05$ & 0 \\
\hline SH11 & $21 \pm 1.13$ & 0 & 0 \\
\hline SH12 & $19 \pm 1.15$ & $19 \pm 1.13$ & $10 \pm 1.14$ \\
\hline
\end{tabular}

(contd...)
Table 1: (Continued)

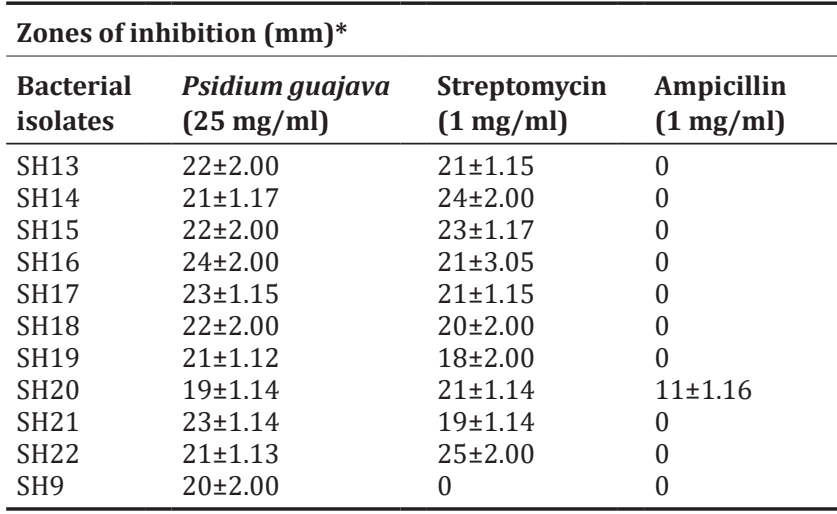

EC1-EC52: Strains of Escherichia coli, SH1-SH22: Strains of Shigella dysenteriae, EC51: Typed culture (ATCC 25922), EC52: Typed culture (NCIB 86),

SH21: Typed culture (ATCC 11311), SH 22: Typed culture (NCIB 197), 0: Not sensitive, *: Mean of three replicates. ATCC: American Type Culture Collection,

NCIB: National Collection of Industrial Bacteria

of Microbiology, Obafemi Awolowo University, Ile-Ife, Nigeria. These organisms included E. coli (NCIB 86), E. coli (ATCC 25922), S. dysenteriae (NCIB 197), and S. dysenteriae (ATCC 11311). The purity of these organisms was done before been used. The preparation of the bacterial strains was done using the colony suspension method as described by European Committee on Antimicrobial Susceptibility Testing.

\section{Culture media used}

The culture media used for this study were nutrient broth (LAB M) and nutrient agar (LAB M) for sub-culturing the bacterial strains. MuellerHinton agar (LAB M) was used for sensitivity testing, eosin methylene blue agar (LAB M) was used to re-confirm E. coli and S. dysenteriae, respectively. All media except Salmonella-Shigella agar were sterilized in an autoclave at $121^{\circ} \mathrm{C}$ for $15 \mathrm{~min}$.

Collection and preparation of plant sample

The fresh stem bark of P. guajava used for this study was collected at Abeokuta, Ogun State, Nigeria, in the month of May 2015. The plant was identified in the Herbarium of Department of Botany, Obafemi Awolowo University, Ile-Ife, Nigeria. The voucher sample of the plant was prepared and deposited in the herbarium for future reference purposes with voucher number IFE-14753. The plant sample was ovendried at $40^{\circ} \mathrm{C}$ until a constant weight of the sample was obtained. The dried sample was later ground into a fine powder and stored in an airtight container for further use.

Extraction of biological active components of the plant sample One thousand and five hundred grams of the powdered sample of the plant were soaked in a mixture of methanol and sterile distilled water in ratio $3: 2(\mathrm{v} / \mathrm{v})$ and left on the laboratory bench for 4 days with regular agitation of the aliquot. The solution collected was filtered into a clean sterile flask and the supernatant collected was concentrated in vacuo using a rotatory evaporator to eliminate the methanol leaving aqueous portion. The aqueous part was then lyophilized to collect the crude extract of the plant sample.

Assessment of photochemical components in the extract from P. guajava stem bark

The assessment of the phytochemicals in the plant extract was done using Trease and Evans [16] and Harborne [17] methods. A small portion of the dry extract was screened for the presence of alkaloids, tannins, steroids, cardiac glycosides, reducing sugars, and saponins.

Fractionation of the crude extract

The crude extract was fractionated using a different organic solvent in order of their polarity, starting with low polar solvent and graduated to the highest polar solvent that is, starting with n-hexane and finished 
Table 2: Sensitivity patterns exhibited by fractions obtained from stem bark extract of Psidium guajava against susceptible bacterial isolates

\begin{tabular}{|c|c|c|c|c|c|}
\hline \multicolumn{6}{|c|}{ Zones of inhibition (mm)* } \\
\hline Bacterial isolates & N-HEX (10 mg/ml) & CHLORO (10 mg/ml) & ETHYL (10 mg/ml) & BUT (10 mg/ml) & AQU $(10 / \mathrm{mg} / \mathrm{ml})$ \\
\hline EC1 & $17 \pm 3.05$ & $19 \pm 4.16$ & $15 \pm 2.31$ & $17 \pm 3.05$ & 0 \\
\hline EC2 & $14 \pm 2.00$ & $15 \pm 3.05$ & $15 \pm 1.15$ & $15 \pm 1.15$ & 0 \\
\hline EC3 & $17 \pm 3.06$ & $17 \pm 5.03$ & $15 \pm 2.31$ & $17 \pm 1.17$ & 0 \\
\hline EC4 & $18 \pm 3.46$ & $21 \pm 1.15$ & $19 \pm 1.13$ & $23 \pm 1.13$ & 0 \\
\hline EC5 & $15 \pm 3.05$ & $14 \pm 2.00$ & $14 \pm 2.00$ & $21 \pm 1.14$ & 0 \\
\hline EC6 & $17 \pm 3.03$ & $16 \pm 2.00$ & $19 \pm 1.14$ & $23 \pm 2.31$ & 0 \\
\hline EC7 & $17 \pm 3.02$ & $14 \pm 2.00$ & $16 \pm 2.00$ & $19 \pm 1.15$ & 0 \\
\hline EC8 & $17 \pm 3.04$ & $19 \pm 1.16$ & $21 \pm 1.15$ & $21 \pm 2.31$ & 0 \\
\hline EC9 & $17 \pm 3.07$ & $18 \pm 2.00$ & $16 \pm 2.00$ & $21 \pm 1.13$ & 0 \\
\hline EC10 & $17 \pm 4.16$ & $19 \pm 1.15$ & $19 \pm 1.17$ & $22 \pm 2.00$ & 0 \\
\hline EC11 & $17 \pm 5.03$ & $17 \pm 2.31$ & $15 \pm 3.05$ & $20 \pm 2.00$ & 0 \\
\hline EC12 & $15 \pm 4.16$ & $15 \pm 2.33$ & $13 \pm 1.14$ & $15 \pm 1.15$ & 0 \\
\hline EC13 & $16 \pm 7.21$ & $19 \pm 3.05$ & $20 \pm 3.46$ & $21 \pm 1.16$ & 0 \\
\hline EC14 & $16 \pm 2.00$ & $19 \pm 4.16$ & $21 \pm 1.16$ & $21 \pm 2.31$ & 0 \\
\hline EC15 & $19 \pm 1.15$ & $17 \pm 4.61$ & $21 \pm 5.03$ & $23 \pm 3.05$ & 0 \\
\hline EC17 & $17 \pm 5.03$ & $18 \pm 3.46$ & $18 \pm 2.00$ & $17 \pm 3.05$ & 0 \\
\hline EC18 & $14 \pm 2.00$ & $17 \pm 4.16$ & $13 \pm 1.15$ & $17 \pm 2.31$ & 0 \\
\hline EC19 & $13 \pm 3.05$ & $16 \pm 2.00$ & $15 \pm 1.17$ & $17 \pm 3.03$ & 0 \\
\hline EC20 & $13 \pm 2.31$ & $15 \pm 2.31$ & $17 \pm 1.14$ & $13 \pm 1.15$ & 0 \\
\hline EC21 & $14 \pm 2.00$ & $16 \pm 2.00$ & $16 \pm 4.00$ & $17 \pm 3.05$ & 0 \\
\hline EC22 & $12 \pm 2.00$ & $15 \pm 3.05$ & $13 \pm 1.15$ & $19 \pm 3.06$ & 0 \\
\hline EC23 & $15 \pm 1.15$ & $13 \pm 3.07$ & $17 \pm 3.05$ & $20 \pm 2.00$ & 0 \\
\hline EC24 & $15 \pm 4.16$ & $17 \pm 3.03$ & $15 \pm 3.03$ & $21 \pm 4.16$ & 0 \\
\hline EC25 & $17 \pm 6.11$ & $17 \pm 1.15$ & $17 \pm 5.03$ & $18 \pm 2.00$ & 0 \\
\hline EC26 & $17 \pm 3.05$ & $17 \pm 3.05$ & $19 \pm 1.15$ & $19 \pm 1.17$ & 0 \\
\hline EC27 & $15 \pm 3.06$ & $13 \pm 2.31$ & $18 \pm 2.00$ & $17 \pm 1.16$ & 0 \\
\hline EC28 & $17 \pm 4.16$ & $16 \pm 2.00$ & $17 \pm 3.05$ & $22 \pm 2.00$ & 0 \\
\hline EC29 & $15 \pm 1.15$ & $13 \pm 1.15$ & $17 \pm 3.07$ & $17 \pm 3.05$ & 0 \\
\hline EC30 & $17 \pm 4.16$ & $19 \pm 1.14$ & $16 \pm 4.00$ & $19 \pm 1.15$ & 0 \\
\hline EC31 & $17 \pm 3.05$ & $17 \pm 2.31$ & $19 \pm 2.31$ & $18 \pm 2.00$ & 0 \\
\hline EC32 & $17 \pm 3.07$ & $17 \pm 2.30$ & $20 \pm 2.00$ & $22 \pm 2.00$ & 0 \\
\hline EC33 & $13 \pm 3.05$ & $18 \pm 4.00$ & $16 \pm 2.00$ & $19 \pm 1.15$ & 0 \\
\hline EC36 & $16 \pm 2.00$ & $22 \pm 2.00$ & $19 \pm 1.15$ & $19 \pm 1.17$ & 0 \\
\hline EC37 & $13 \pm 3.05$ & $18 \pm 2.00$ & $15 \pm 2.31$ & $19 \pm 1.14$ & 0 \\
\hline EC38 & $15 \pm 3.07$ & $20 \pm 2.00$ & $20 \pm 2.00$ & $17 \pm 1.13$ & 0 \\
\hline EC39 & $13 \pm 3.05$ & $20 \pm 2.00$ & $21 \pm 1.15$ & $22 \pm 2.00$ & 0 \\
\hline EC40 & $15 \pm 3.07$ & $22 \pm 2.00$ & $19 \pm 2.31$ & $21 \pm 1.15$ & 0 \\
\hline EC41 & $13 \pm 3.03$ & $20 \pm 2.00$ & $18 \pm 2.00$ & $22 \pm 2.00$ & 0 \\
\hline EC42 & $16 \pm 5.29$ & $21 \pm 1.15$ & $19 \pm 3.05$ & $21 \pm 1.16$ & 0 \\
\hline EC43 & $15 \pm 5.03$ & $19 \pm 3.05$ & $19 \pm 1.15$ & $19 \pm 1.17$ & 0 \\
\hline EC44 & $16 \pm 2.00$ & $17 \pm 3.07$ & $19 \pm 2.31$ & $21 \pm 1.15$ & 0 \\
\hline EC45 & $16 \pm 3.46$ & $17 \pm 1.15$ & $17 \pm 3.05$ & $19 \pm 1.14$ & 0 \\
\hline EC46 & $13 \pm 3.05$ & $13 \pm 4.16$ & $17 \pm 3.06$ & $18 \pm 2.00$ & 0 \\
\hline EC47 & $15 \pm 3.06$ & $19 \pm 4.17$ & $19 \pm 3.07$ & $20 \pm 2.00$ & 0 \\
\hline EC48 & $17 \pm 2.31$ & $18 \pm 2.00$ & $21 \pm 2.31$ & $19 \pm 1.15$ & 0 \\
\hline EC49 & $16 \pm 2.00$ & $16 \pm 2.00$ & $22 \pm 2.00$ & $17 \pm 1.16$ & 0 \\
\hline EC50 & $17 \pm 3.05$ & $24 \pm 2.00$ & $25 \pm 3.05$ & $20 \pm 2.00$ & 0 \\
\hline EC51 & $17 \pm 3.05$ & $17 \pm 2.31$ & $19 \pm 2.31$ & $18 \pm 2.00$ & 0 \\
\hline EC52 & $15 \pm 3.07$ & $20 \pm 2.00$ & $20 \pm 2.00$ & $17 \pm 1.13$ & 0 \\
\hline SH1 & $19 \pm 1.15$ & $20 \pm 2.00$ & $19 \pm 1.15$ & $24 \pm 2.00$ & 0 \\
\hline $\mathrm{SH} 2$ & $19 \pm 3.05$ & $19 \pm 1.15$ & $17 \pm 3.05$ & $21 \pm 1.15$ & 0 \\
\hline SH3 & $21 \pm 1.16$ & $18 \pm 2.00$ & $17 \pm 1.13$ & $24 \pm 2.00$ & 0 \\
\hline SH4 & $17 \pm 1.17$ & $18 \pm 2.00$ & $19 \pm 1.16$ & $23 \pm 2.31$ & 0 \\
\hline SH5 & $17 \pm 3.05$ & $14 \pm 2.00$ & $14 \pm 2.00$ & $19 \pm 2.30$ & 0 \\
\hline SH6 & $18 \pm 2.00$ & $19 \pm 1.14$ & $16 \pm 2.00$ & $20 \pm 2.00$ & 0 \\
\hline SH7 & $19 \pm 1.14$ & $19 \pm 1.13$ & $17 \pm 2.31$ & $23 \pm 1.14$ & 0 \\
\hline SH8 & $20 \pm 2.00$ & $21 \pm 1.17$ & $16 \pm 2.00$ & $21 \pm 1.16$ & 0 \\
\hline SH9 & $19 \pm 1.15$ & $20 \pm 0.00$ & $17 \pm 1.15$ & $23 \pm 1.17$ & 0 \\
\hline SH10 & $19 \pm 1.16$ & $18 \pm 2.00$ & $15 \pm 1.16$ & $23 \pm 2.31$ & 0 \\
\hline SH11 & $19 \pm 1.17$ & $19 \pm 1.13$ & $18 \pm 3.46$ & $20 \pm 2.00$ & 0 \\
\hline SH12 & $21 \pm 1.12$ & $17 \pm 1.16$ & $16 \pm 2.00$ & $19 \pm 1.15$ & 0 \\
\hline SH13 & $21 \pm 1.13$ & $19 \pm 1.15$ & $15 \pm 1.16$ & $21 \pm 1.17$ & 0 \\
\hline SH14 & $17 \pm 1.15$ & $21 \pm 1.17$ & $15 \pm 1.17$ & $23 \pm 1.13$ & 0 \\
\hline SH15 & $19 \pm 1.17$ & $20 \pm 2.00$ & $14 \pm 2.00$ & $21 \pm 1.12$ & 0 \\
\hline
\end{tabular}


Table 2: (Continued)

\begin{tabular}{|c|c|c|c|c|c|}
\hline Bacterial isolates & N-HEX $(10 \mathrm{mg} / \mathrm{ml})$ & CHLORO $(10 \mathrm{mg} / \mathrm{ml})$ & ETHYL $(10 \mathrm{mg} / \mathrm{ml})$ & BUT $(10 \mathrm{mg} / \mathrm{ml})$ & $\mathrm{AQU}(10 / \mathrm{mg} / \mathrm{ml})$ \\
\hline SH16 & $17 \pm 3.05$ & $21 \pm 1.17$ & $17 \pm 1.13$ & $21 \pm 1.16$ & 0 \\
\hline SH17 & $18 \pm 2.00$ & $20 \pm 2.00$ & $19 \pm 1.17$ & $23 \pm 1.14$ & 0 \\
\hline SH18 & $20 \pm 2.00$ & $19 \pm 1.16$ & $19 \pm 1.14$ & $24 \pm 2.00$ & 0 \\
\hline SH19 & $19 \pm 1.15$ & $18 \pm 2.00$ & $17 \pm 1.15$ & $23 \pm 1.15$ & 0 \\
\hline SH20 & $21 \pm 1.14$ & $19 \pm 1.15$ & $19 \pm 1.16$ & $23 \pm 1.17$ & 0 \\
\hline SH21 & $21 \pm 1.16$ & $18 \pm 2.00$ & $17 \pm 1.13$ & $24 \pm 2.00$ & 0 \\
\hline SH22 & $20 \pm 2.00$ & $21 \pm 1.17$ & $16 \pm 2.00$ & $21 \pm 1.16$ & 0 \\
\hline
\end{tabular}

EC1-EC52: Strains of Escherichia coli, SH1-SH22: Strains of Shigella dysenteriae, EC51: Typed culture (ATCC 25922), EC52: Typed culture (NCIB 86), S21: Typed culture (ATCC 11311), SH22: Typed culture (NCIB 197), N-HEX: n-Hexane fraction, CHLORO: Chloroform fraction, ETHYL: Ethyl acetate fraction, BUT: Butanol fraction, AQU: Aqueous fraction, 0: Not sensitive, *: Mean of three replicates. ATCC: American Type Culture Collection, NCIB: National Collection of Industrial Bacteria

Table 3: The minimum inhibitory concentrations exhibited by crude stem bark extract and active fractions of Psidium guajava against susceptible bacterial isolates

\begin{tabular}{|c|c|c|c|c|c|}
\hline $\begin{array}{l}\text { Bacterial } \\
\text { isolates }\end{array}$ & $\begin{array}{l}\mathrm{CE} \\
(\mathrm{mg} / \mathrm{ml})\end{array}$ & $\begin{array}{l}\text { N-HEX } \\
(\mathrm{mg} / \mathrm{ml})\end{array}$ & $\begin{array}{l}\text { CHLORO } \\
(\mathrm{mg} / \mathrm{ml})\end{array}$ & $\begin{array}{l}\text { ETHYL } \\
(\mathrm{mg} / \mathrm{ml})\end{array}$ & $\begin{array}{l}\text { BUT } \\
(\mathrm{mg} / \mathrm{ml})\end{array}$ \\
\hline EC1 & 1.56 & 0.31 & 0.31 & 1.25 & 0.31 \\
\hline $\mathrm{EC} 2$ & 1.56 & 0.31 & 0.63 & 0.31 & 0.63 \\
\hline EC3 & 3.13 & 2.50 & 2.50 & 2.50 & 2.50 \\
\hline EC4 & 3.13 & 2.50 & 1.25 & 2.50 & 0.63 \\
\hline EC5 & 12.5 & 5.00 & 2.50 & 1.25 & 2.50 \\
\hline EC6 & 1.56 & 1.25 & 2.50 & 1.25 & 1.25 \\
\hline EC7 & 6.25 & 2.50 & 5.00 & 2.50 & 0.63 \\
\hline EC8 & 1.56 & 0.63 & 2.50 & 1.25 & 0.31 \\
\hline EC9 & 1.56 & 0.63 & 2.50 & 1.25 & 2.50 \\
\hline EC10 & 6.25 & 5.00 & 1.25 & 2.50 & 0.63 \\
\hline EC11 & 6.25 & 2.50 & 2.50 & 1.25 & 1.25 \\
\hline EC12 & 3.13 & 1.25 & 2.50 & 2.50 & 1.25 \\
\hline EC13 & 1.56 & 0.63 & 1.25 & 1.25 & 0.31 \\
\hline EC14 & 3.13 & 1.25 & 2.50 & 2.50 & 0.63 \\
\hline EC15 & 1.56 & 0.63 & 1.25 & 1.25 & 0.31 \\
\hline EC16 & 3.13 & 2.50 & 1.25 & 2.50 & 1.25 \\
\hline EC17 & 6.25 & 2.50 & 0.63 & 1.25 & 2.50 \\
\hline EC18 & 1.56 & 0.31 & 1.25 & 1.25 & 0.63 \\
\hline EC19 & 3.13 & 1.25 & 2.50 & 1.25 & 1.25 \\
\hline EC20 & 1.56 & 0.31 & 0.63 & 0.63 & 0.31 \\
\hline EC21 & 3.13 & 1.25 & 2.50 & 2.50 & 1.25 \\
\hline EC22 & 12.5 & 5.00 & 2.50 & 5.00 & 2.50 \\
\hline EC23 & 6.25 & 2.50 & 5.00 & 2.50 & 0.63 \\
\hline EC24 & 3.13 & 2.50 & 1.25 & 2.50 & 1.25 \\
\hline EC25 & 6.25 & 2.50 & 2.50 & 1.25 & 1.25 \\
\hline EC26 & 12.5 & 5.00 & 2.50 & 5.00 & 2.50 \\
\hline EC27 & 3.13 & 1.25 & 1.25 & 2.50 & 0.63 \\
\hline EC28 & 6.25 & 2.50 & 2.50 & 1.25 & 1.25 \\
\hline EC29 & 6.25 & 1.25 & 2.50 & 2.50 & 1.25 \\
\hline EC30 & 3.13 & 1.25 & 1.25 & 1.25 & 1.25 \\
\hline EC31 & 12.5 & 5.00 & 2.50 & 2.50 & 1.25 \\
\hline EC32 & 3.13 & 1.25 & 2.50 & 1.25 & 0.63 \\
\hline EC33 & 1.56 & 0.31 & 1.25 & 0.63 & 0.31 \\
\hline EC34 & 6.25 & 2.50 & 2.50 & 2.50 & 1.25 \\
\hline EC35 & 3.13 & 1.25 & 1.25 & 1.25 & 0.63 \\
\hline EC36 & 12.5 & 2.50 & 5.00 & 2.50 & 2.50 \\
\hline EC37 & 3.13 & 1.25 & 1.25 & 0.63 & 1.25 \\
\hline EC38 & 12.5 & 5.00 & 2.50 & 5.00 & 1.25 \\
\hline EC39 & 3.13 & 1.25 & 2.50 & 2.50 & 1.25 \\
\hline EC40 & 6.25 & 2.50 & 0.31 & 0.63 & 0.63 \\
\hline EC41 & 3.13 & 1.25 & 0.63 & 2.50 & 1.25 \\
\hline EC42 & 6.25 & 2.50 & 2.50 & 1.25 & 0.31 \\
\hline EC43 & 3.13 & 1.25 & 1.25 & 0.63 & 1.25 \\
\hline EC44 & 3.13 & 2.50 & 2.50 & 1.25 & 1.25 \\
\hline EC45 & 12.5 & 5.00 & 2.50 & 5.00 & 2.50 \\
\hline EC46 & 6.25 & 1.25 & 5.00 & 2.50 & 1.25 \\
\hline EC47 & 12.5 & 5.00 & 2.50 & 5.00 & 2.50 \\
\hline EC48 & 12.5 & 2.50 & 5.00 & 2.50 & 2.50 \\
\hline
\end{tabular}

(contd...)
Table 3: (Continued)

\begin{tabular}{|c|c|c|c|c|c|}
\hline $\begin{array}{l}\text { Bacterial } \\
\text { isolates }\end{array}$ & $\begin{array}{l}\mathrm{CE} \\
(\mathrm{mg} / \mathrm{ml})\end{array}$ & $\begin{array}{l}\text { N-HEX } \\
(\mathrm{mg} / \mathrm{ml})\end{array}$ & $\begin{array}{l}\text { CHLORO } \\
(\mathrm{mg} / \mathrm{ml})\end{array}$ & $\begin{array}{l}\text { ETHYL } \\
(\mathrm{mg} / \mathrm{ml})\end{array}$ & $\begin{array}{l}\text { BUT } \\
(\mathrm{mg} / \mathrm{ml})\end{array}$ \\
\hline EC49 & 6.25 & 1.25 & 0.63 & 0.63 & 1.25 \\
\hline EC50 & 3.13 & 0.63 & 2.50 & 1.25 & 2.50 \\
\hline EC51 & 6.25 & 1.25 & 2.50 & 2.50 & 1.25 \\
\hline EC52 & 3.13 & 0.63 & 0.31 & 2.50 & 0.63 \\
\hline SH1 & 6.25 & 1.25 & 1.25 & 2.50 & 1.25 \\
\hline $\mathrm{SH} 2$ & 3.13 & 2.50 & 2.50 & 1.25 & 2.50 \\
\hline SH3 & 6.25 & 0.63 & 1.25 & 0.63 & 1.25 \\
\hline $\mathrm{SH} 4$ & 1.56 & 0.31 & 0.63 & 1.25 & 0.31 \\
\hline SH5 & 3.13 & 0.63 & 1.25 & 2.50 & 1.25 \\
\hline SH6 & 6.25 & 1.25 & 0.63 & 5.00 & 0.63 \\
\hline SH7 & 3.13 & 0.63 & 2.50 & 1.25 & 1.25 \\
\hline SH8 & 1.56 & 0.31 & 1.25 & 0.63 & 0.31 \\
\hline SH9 & 12.5 & 5.00 & 2.50 & 2.50 & 1.25 \\
\hline SH10 & 1.56 & 0.31 & 1.25 & 1.25 & 0.63 \\
\hline SH11 & 3.13 & 0.63 & 0.31 & 1.25 & 0.63 \\
\hline SH12 & 12.5 & 2.50 & 5.00 & 5.00 & 2.50 \\
\hline SH13 & 3.13 & 0.63 & 0.63 & 2.50 & 1.25 \\
\hline SH14 & 6.25 & 1.25 & 2.50 & 1.25 & 0.63 \\
\hline SH15 & 6.25 & 2.50 & 2.50 & 1.25 & 1.25 \\
\hline SH16 & 3.13 & 0.31 & 0.63 & 0.63 & 0.31 \\
\hline SH17 & 3.13 & 0.63 & 1.25 & 0.63 & 0.63 \\
\hline SH18 & 12.5 & 5.00 & 2.50 & 5.00 & 2.50 \\
\hline SH19 & 12.5 & 2.50 & 2.50 & 5.00 & 2.50 \\
\hline SH20 & 3.13 & 0.63 & 1.25 & 0.63 & 0.63 \\
\hline SH21 & 3.13 & 0.31 & 2.50 & 1.25 & 1.25 \\
\hline SH22 & 6.25 & 1.25 & 2.50 & 1.25 & 0.63 \\
\hline
\end{tabular}

EC1-EC52: Strains of Escherichia coli, SH1-SH22: Strains of Shigella dysenteriae, EC51: Typed culture (ATCC 25922), EC52: Typed culture (NCIB 86), SH21: Typed culture (ATCC 11311), SH22: Typed culture (NCIB 197), N-HEX: n-Hexane fraction, CHLORO: Chloroform fraction, ETHYL: Ethyl acetate fraction, BUT: Butanol fraction. ATCC: American Type Culture Collection, NCIB: National Collection of Industrial Bacteria

up with n-butanol. The fractions obtained were kept in an air-tight container in a refrigerator at $5^{\circ} \mathrm{C}$ for further use.

Determination of the antibacterial potency of the crude extract and fractions obtained from it

The antibacterial tests were done using agar-well diffusion methods [18]. The test organisms were re-activated in nutrient broth for $18 \mathrm{~h}$ before use. Exactly $0.1 \mathrm{ml}$ of standardized test bacterial strains $\left(10^{6} \mathrm{cfu} / \mathrm{mL}\right.$ of $0.5 \mathrm{McFarland}$ standard) was transferred into MuellerHinton agar medium at $40^{\circ} \mathrm{C}$. This was thoroughly mixed together and later poured into pre-sterilized Petri dishes. The plates were allowed to set and wells were bored into the medium using $6 \mathrm{~mm}$ sterile cork borer. These wells were then filled up with the prepared solutions of the crude extract and the fractions. Care was taken not to allow the solution to spill on the surface of the medium. The final concentrations of the crude extract and the fractions used were $25 \mathrm{mg} / \mathrm{mL}$ and $10 \mathrm{mg} / \mathrm{mL}$, respectively. On the other hand, ampicillin and streptomycin were used 
Table 4: The minimum bactericidal concentrations exhibited by crude stem bark extract and active fractions of Psidium guajava against susceptible bacterial isolates

\begin{tabular}{|c|c|c|c|c|c|}
\hline $\begin{array}{l}\text { Bacterial } \\
\text { isolates }\end{array}$ & $\begin{array}{l}\text { CE } \\
(\mathrm{mg} / \mathrm{ml})\end{array}$ & $\begin{array}{l}\text { N-HEX } \\
(\mathrm{mg} / \mathrm{ml})\end{array}$ & $\begin{array}{l}\text { CHLORO } \\
\text { (mg/ml) }\end{array}$ & $\begin{array}{l}\text { ETHYL } \\
(\mathrm{mg} / \mathrm{ml})\end{array}$ & $\begin{array}{l}\text { BUT } \\
(\mathrm{mg} / \mathrm{ml})\end{array}$ \\
\hline EC1 & 3.13 & 0.63 & 0.63 & 2.50 & 0.63 \\
\hline EC2 & 3.13 & 0.63 & 1.25 & 0.63 & 1.25 \\
\hline EC3 & 6.25 & 5.00 & 5.00 & 5.00 & 5.00 \\
\hline EC4 & 6.25 & 5.00 & 2.50 & 5.00 & 1.25 \\
\hline EC5 & ND & ND & 5.00 & 2.50 & 5.00 \\
\hline EC6 & 3.13 & 2.50 & 5.00 & 2.50 & 2.50 \\
\hline EC7 & 12.5 & 5.00 & ND & 5.00 & 1.25 \\
\hline EC8 & 3.13 & 1.25 & 5.00 & 2.50 & 0.63 \\
\hline EC9 & 3.13 & 1.25 & 5.00 & 2.50 & 5.00 \\
\hline EC10 & 12.5 & ND & 2.50 & 5.00 & 1.25 \\
\hline EC11 & 12.5 & 5.00 & 5.00 & 2.50 & 2.50 \\
\hline EC12 & 6.25 & 2.50 & 5.00 & 5.00 & 2.50 \\
\hline EC13 & 3.13 & 1.25 & 2.50 & 2.50 & 0.63 \\
\hline EC14 & 6.25 & 2.50 & 5.00 & 5.00 & 1.25 \\
\hline EC15 & 3.13 & 1.25 & 2.50 & 2.50 & 0.63 \\
\hline EC16 & 6.25 & 5.00 & 2.50 & 5.00 & 2.50 \\
\hline EC17 & 12.5 & 5.00 & 1.25 & 2.50 & 5.00 \\
\hline EC18 & 3.13 & 0.63 & 2.50 & 2.50 & 1.25 \\
\hline EC19 & 6.25 & 2.50 & 5.00 & 2.50 & 2.50 \\
\hline EC20 & 3.13 & 0.31 & 0.63 & 0.63 & 0.31 \\
\hline EC21 & 6.25 & 2.50 & 5.00 & 5.00 & 2.50 \\
\hline EC22 & ND & ND & 5.00 & ND & 5.00 \\
\hline EC23 & 12.5 & 5.00 & ND & 5.00 & 1.25 \\
\hline EC24 & 6.25 & 5.00 & 2.50 & 5.00 & 2.50 \\
\hline EC25 & 12.5 & 5.00 & 5.00 & 2.50 & 2.50 \\
\hline EC26 & ND & ND & 5.00 & ND & 5.00 \\
\hline EC27 & 6.25 & 2.50 & 2.50 & 5.00 & 1.25 \\
\hline EC28 & 12.5 & 5.00 & 5.00 & 2.50 & 2.50 \\
\hline EC29 & 12.5 & 2.50 & 5.00 & 5.00 & 2.50 \\
\hline EC30 & 6.25 & 2.50 & 2.50 & 2.50 & 2.50 \\
\hline EC31 & ND & ND & 5.00 & 5.00 & 2.50 \\
\hline EC32 & 6.25 & 2.50 & 5.00 & 2.50 & 1.25 \\
\hline EC33 & 6.25 & 0.63 & 2.50 & 1.25 & 0.63 \\
\hline EC34 & 12.5 & 5.00 & 5.00 & 5.00 & 2.50 \\
\hline EC35 & 6.25 & 2.50 & 2.50 & 2.50 & 1.25 \\
\hline EC36 & ND & 5.00 & ND & 5.00 & 5.00 \\
\hline EC37 & 6.25 & 2.50 & 2.50 & 1.25 & 2.50 \\
\hline EC38 & ND & ND & 5.00 & ND & 2.50 \\
\hline EC39 & 6.25 & 2.50 & 5.00 & 5.00 & 2.50 \\
\hline EC40 & 12.5 & 5.00 & 0.63 & 1.25 & 1.25 \\
\hline EC41 & 6.25 & 2.50 & 1.25 & 5.00 & 2.50 \\
\hline EC42 & 12.5 & 5.00 & 5.00 & 2.50 & 0.63 \\
\hline EC43 & 6.25 & 2.50 & 2.50 & 1.25 & 2.50 \\
\hline EC44 & 6.25 & 5.00 & 5.00 & 2.50 & 2.50 \\
\hline EC45 & 25.0 & ND & 5.00 & ND & 5.00 \\
\hline EC46 & 12.5 & 2.50 & ND & 5.00 & 2.50 \\
\hline EC47 & ND & ND & 5.00 & ND & 5.00 \\
\hline EC48 & ND & 5.00 & ND & 5.00 & 5.00 \\
\hline EC49 & 12.5 & 2.50 & 1.25 & 1.25 & 2.50 \\
\hline EC50 & 6.25 & 1.25 & 5.00 & 2.50 & 5.00 \\
\hline EC51 & 12.5 & 2.50 & 5.00 & 5.00 & 2.50 \\
\hline EC52 & 6.25 & 1.25 & 0.63 & 5.00 & 1.25 \\
\hline SH1 & 12.5 & 2.50 & 2.50 & 5.00 & 2.50 \\
\hline $\mathrm{SH} 2$ & 6.25 & 5.00 & 5.00 & 2.50 & 5.00 \\
\hline SH3 & 12.5 & 1.25 & 2.50 & 1.25 & 2.50 \\
\hline SH4 & 3.13 & 0.63 & 1.25 & 2.50 & 0.63 \\
\hline SH5 & 6.25 & 1.25 & 2.50 & 5.00 & 2.50 \\
\hline SH6 & 12.5 & 2.50 & 1.25 & ND & 1.25 \\
\hline SH7 & 6.25 & 1.25 & 5.00 & 2.50 & 2.50 \\
\hline SH8 & 3.13 & 0.63 & 2.50 & 1.25 & 0.63 \\
\hline SH9 & ND & ND & 5.00 & 5.00 & 2.50 \\
\hline SH10 & 3.13 & 0.63 & 2.50 & 2.50 & 1.25 \\
\hline SH11 & 6.25 & 1.25 & 0.63 & 2.50 & 1.25 \\
\hline SH12 & ND & 5.00 & ND & ND & 5.00 \\
\hline SH13 & 6.25 & 1.25 & 1.25 & 5.00 & 2.50 \\
\hline SH14 & 12.5 & 2.50 & 5.00 & 2.50 & 1.25 \\
\hline
\end{tabular}

Table 4: (Continued)

\begin{tabular}{llllll}
\hline $\begin{array}{l}\text { Bacterial } \\
\text { isolates }\end{array}$ & $\begin{array}{l}\text { CE } \\
(\mathbf{m g} / \mathbf{m l})\end{array}$ & $\begin{array}{l}\text { N-HEX } \\
(\mathbf{m g} / \mathbf{m l})\end{array}$ & $\begin{array}{l}\text { CHLORO } \\
(\mathbf{m g} / \mathbf{m l})\end{array}$ & $\begin{array}{l}\text { ETHYL } \\
(\mathbf{m g} / \mathbf{m l})\end{array}$ & $\begin{array}{l}\text { BUT } \\
(\mathbf{m g} / \mathbf{m l})\end{array}$ \\
\hline SH15 & 12.5 & 5.00 & 5.00 & 2.50 & 2.50 \\
SH16 & 6.25 & 0.63 & 1.25 & 1.25 & 0.63 \\
SH17 & 6.25 & 1.25 & 2.50 & 1.25 & 1.25 \\
SH18 & ND & ND & 5.00 & ND & 5.00 \\
SH19 & ND & 5.00 & 5.00 & ND & 5.00 \\
SH20 & 6.25 & 1.25 & 2.50 & 1.25 & 1.25 \\
SH21 & 6.25 & 0.63 & 5.00 & 2.50 & 2.50 \\
SH22 & 12.5 & 2.50 & 5.00 & 2.50 & 1.25 \\
\hline
\end{tabular}

EC1-EC52: Strains of Escherichia coli, SH1-SH22: Strains of Shigella dysenteriae, EC51: Typed culture (ATCC 25922), EC52: Typed culture (NCIB 86), SH21: Typed culture (ATCC 11311) SH22: Typed culture (NCIB 197); N-HEX: n-Hexane fraction, CHLORO: Chloroform fraction, ETHYL: Ethyl acetate fraction, BUT: Butanol fraction, ND: Not done. ATCC: American Type Culture Collection, NCIB: National Collection of Industrial Bacteria

Table 5: Phytochemical compounds exhibited by the extract

\begin{tabular}{ll}
\hline Phytochemical test & Results \\
\hline Alkaloids & Positive \\
Saponins & Positive \\
Tannins & Positive \\
Steroids & Positive \\
Flavonoids & Positive \\
Reducing sugars & Positive \\
Cardiac glycosides & Positive \\
\hline
\end{tabular}

as positive controls at a concentration of $1 \mathrm{mg} / \mathrm{mL}$. The plates were left on the laboratory bench for $1 \mathrm{~h}$ to allow proper in-flow of the solution into the medium before incubating them at $37^{\circ} \mathrm{C}$ for $24 \mathrm{~h}$. The plates were not stock-piled to allow even distribution of temperature round the plates to avoid false results. The plates were later observed for zones of inhibition which is an indication of susceptibility of the test organisms to the extracts.

Assessment of minimum inhibitory concentrations (MIC) of the crude extract and fractions against susceptible organisms

Two-fold dilution of the crude extract and fractions was adopted to determine their MIC [19]. Two milliliters of different concentrations of the solution were added to $18 \mathrm{~mL}$ of pre-sterilized molten nutrient agar to give the final concentrations ranging between $0.31 \mathrm{mg} / \mathrm{mL}-5.00 \mathrm{mg} / \mathrm{mL}$ for the fractions and $1.56 \mathrm{mg} / \mathrm{mL}-12.5 \mathrm{mg} / \mathrm{mL}$ for crude extract. The mixture was then poured into well-labeled sterile Petri dishes and allowed to solidify. The plates were left on the laboratory bench overnight to ascertain their purity. The surfaces of the plates were allowed to dry before streaking with the standardized inoculums of the organisms and incubated aerobically at $37^{\circ} \mathrm{C}$ for $48 \mathrm{~h}$. The plates were later examined for the presence or absence of bacterial growth. The MIC was taken as the lowest concentration of the fraction that inhibited the growth of the organisms.

Assessment of minimum bactericidal concentration (MBC) of the crude extract and fractions against susceptible organisms

The MBC of the fractions and the crude extract was assessed by taken sample from streaked line of the MIC test and cultured on fresh sterile nutrient agar medium. The plates were incubated at $37^{\circ} \mathrm{C}$ for $72 \mathrm{~h}$. The MBC was taken as the concentrations of the fraction that did not support any bactericidal growth of the medium.

Determination of the killing rate of bacterial strains by the fractions

The test was carried out using test bacterial strains, that is, E. coli and $S$. dysenteriae on their viability against different concentrations of fractions relative to their MIC [18]. Viable counts of the test organisms were initially determined to standardize the inoculums. Exactly $0.5 \mathrm{~mL}$ volume of unknown cell density (by viable counts $10^{6} \mathrm{cfu} / \mathrm{mL}$ ) was added to $4.5 \mathrm{~mL}$ of different concentrations of the fraction relative 


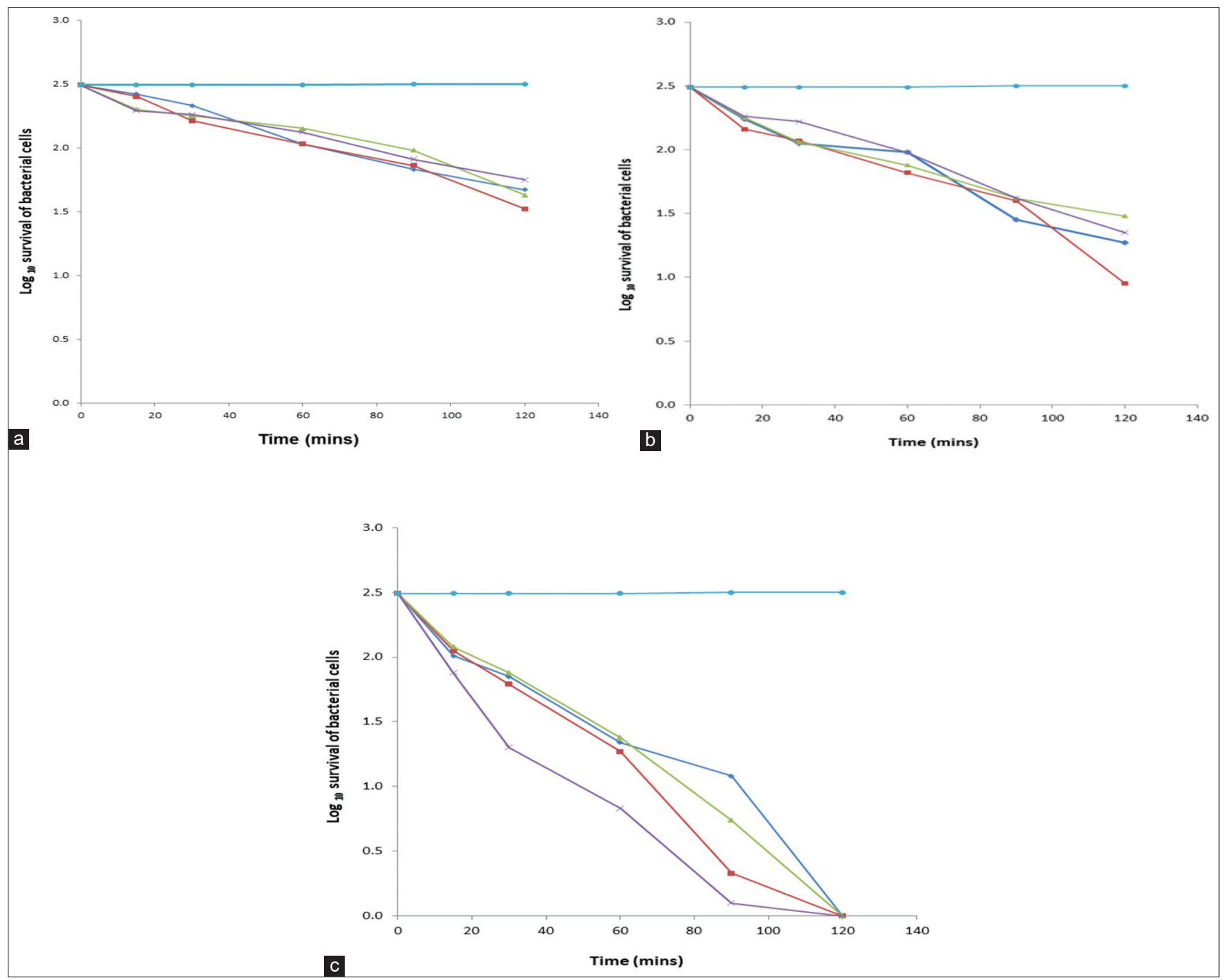

Fig. 1: (a) The extent and the rate of killing of Escherichia coli by n-hexane fraction ( - ), chloroform fraction $(-\infty)$, ethyl acetate fraction (- - ), butanol fraction (-), and control (- - ) at $\times 1$ minimum inhibitory concentrations (MIC). Each point represents the $\log _{10}$ of mean survival of bacterial cells at a particular time interval in the presence of the fractions. (b) The extent and the rate of killing of $E$. coli by $\mathrm{n}$-hexane fraction ( - ), chloroform fraction $(--)$, ethyl acetate fraction (- - ), butanol fraction (-) and control (-) at $\times 2$ MIC. Each point represents the $\log _{10}$ of mean survival of bacterial cells at a particular time interval in the presence of the fractions. (c) The extent and the rate of killing of $E$. coli by n-hexane fraction ( - ), chloroform fraction ( - -), ethyl acetate fraction (- - ), butanol fraction $(-)$, and control (-) at $\times 3$ MIC. Each point represents the $\log _{10}$ of mean survival of bacterial cells at a particular time interval in the presence of the fractions

to MIC. The suspension was thoroughly mixed and held at room temperature $\left(28-30^{\circ} \mathrm{C}\right)$ for $2 \mathrm{~h}$ to determine the killing rate of the test organisms. Exactly $0.5 \mathrm{~mL}$ of each suspension was withdrawn at the appropriate time intervals and transferred to $4.5 \mathrm{~mL}$ nutrient broth recovery medium containing $3 \%$ "Tween 80 " to neutralize the effects of the fractions carry-over from the bacterial cells. The suspension was shaken properly and then serially diluted up to $10^{-5}$ in sterile physiological saline and plated out for viable counts. The plates were incubated at $37^{\circ} \mathrm{C}$ for $48 \mathrm{~h}$ before determining the survival cells. Control experiment was set up without the inclusion of the fractions. Viable counts were made in triplicates for each sample and compared with the counts of the control. Depression in viable counts indicated killing by the fractions.

Determination of protein leakage from the bacterial strains by the fractions

The test bacterial strains cells were (E. coli and $S$. dysenteriae) separately washed in $0.9 \%(\mathrm{w} / \mathrm{v})$ normal saline to remove any presence of slime layer from the cells. These washed cells (inoculum size approximately $10^{6}$ cells 0.5 McFarland standards) were treated with various concentrations of the fraction relative to the MIC at various time intervals for $2 \mathrm{~h}$. Each suspension was later centrifuge at $7000 \mathrm{rpm}$ to collect the supernatant for protein assaying [20]. The standard curve for protein analysis was constructed to quantify the quality of protein leaked from the bacterial cells. Exactly $0.4 \mathrm{~mL}$ Bradford reagent was added to $1.6 \mathrm{~mL}$ sample $(0.2 \mathrm{~mL}$ supernatant added to $1.4 \mathrm{~mL}$ sterilized distilled water) to make up $2 \mathrm{~mL}$ total volume. Optical density (OD) of the resulting solution was thereafter taking at $595 \mathrm{~nm}$ after $5 \mathrm{~min}$ of preparation but not later than $1 \mathrm{~h}$. The OD of each of the samples was calculated from the equation of the best-fit linear regression line obtained from the graph of the bovine serum albumin (BSA) standard curve.

Preparation of the BSA standard curve for the quantification of protein leaked out of the bacterial cells

Exactly $100 \mathrm{ug} / \mathrm{mL}$ concentration of BSA stock solution was prepared and varying concentrations were made from the stock solution. A $0.4 \mathrm{~mL}$ of Bradford reagent was added to the various BSA concentrations. This 


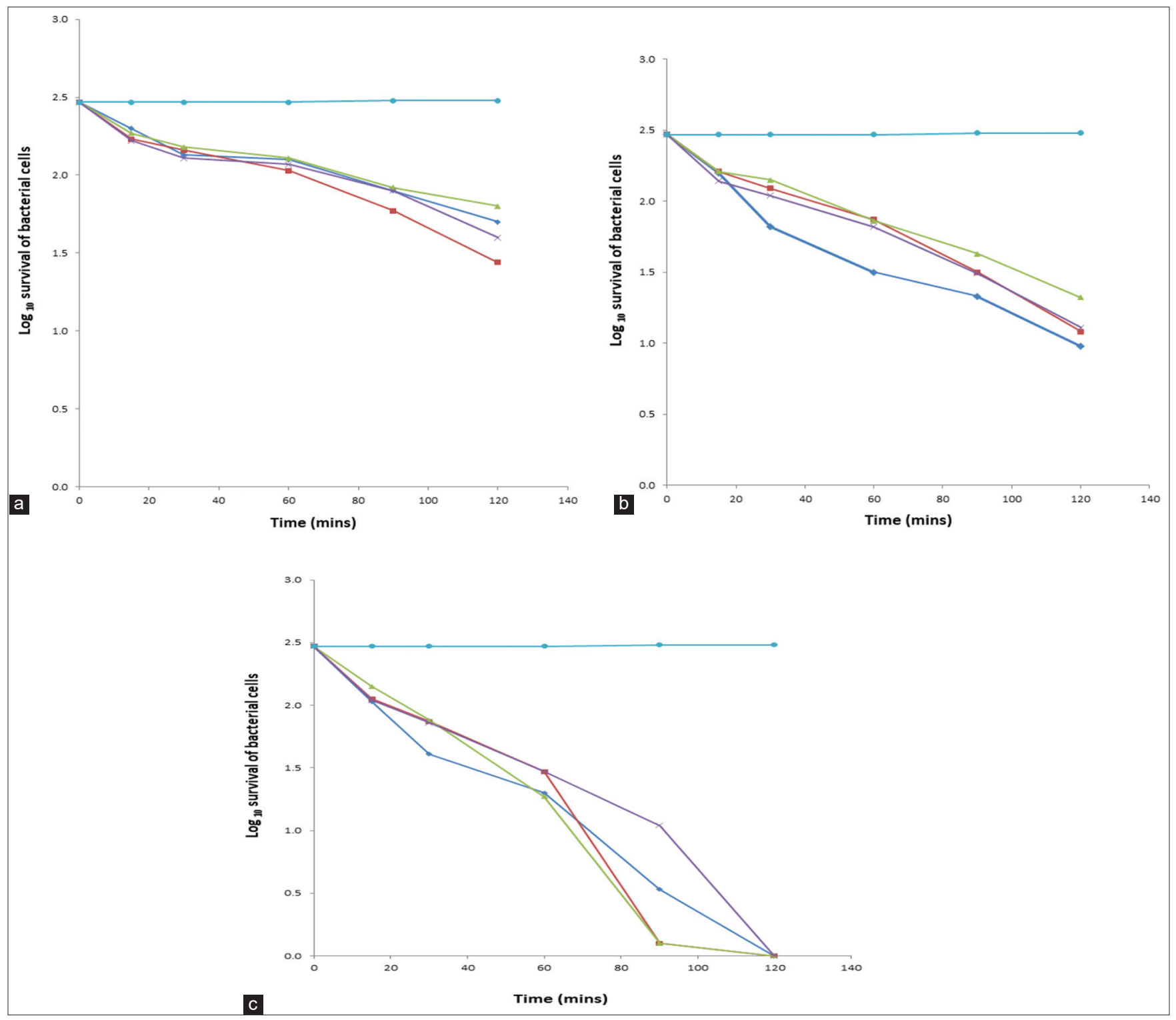

Fig. 2: (a) The extent and the rate of killing of Shigella dysenteriae by n-hexane fraction $(\longrightarrow \sim)$, chloroform fraction $(-\longrightarrow)$, ethyl acetate fraction $(-)$, butanol fraction $(-)$, and control $(-)$ at $\times 1$ minimum inhibitory concentrations (MIC). Each point represents the $\log _{10}$ of mean survival of bacterial cells at a particular time interval in the presence of the fractions. (b) The extent and the rate of killing of $S$. dysenteriae by n-hexane fraction ( - ), chloroform fraction $(--)$ ), ethyl acetate fraction ( - ), butanol fraction (-), and control (-) at $\times 2$ MIC. Each point represents the $\log _{10}$ of mean survival of bacterial cells at a particular time interval in the presence of the fractions. (c) The extent and the rate of killing of $S$. dysenteriae by $n$-hexane fraction ( - ), chloroform fraction (- - ), ethyl acetate fraction $(--)$, butanol fraction $(-)$, and control $(-\infty)$ at $\times 3$ MIC. Each point represents the $\log _{10}$ of mean survival of bacterial cells at a particular time interval in the presence of the fractions

was allowed to stand for 5 min after which the OD was measured at $600 \mathrm{~nm}$. The various OD values obtained were then plotted against BSA concentrations to form a standard albumin curve. The concentrations of proteins in the samples were then calculated from the equation of the best-fit linear regression line obtained from the graph of the BSA standard curve.

Determination of potassium ions leakage from the bacterial cells by the fractions

Eighteen-hour old cells of $E$. coli and $S$. dysenteriae were washed 3 times in physiological saline to remove slime layers from the cells. Exactly $50 \mathrm{~mL}$ of washed cells (OD $470 \mathrm{~nm}=1.5$ ) was dispensed into a clean beaker which was magnetically stirred. Fifty milliliters of ionic strength adjustment buffer (18.37 g of tetraethylammonium chloride in deionized water and made up to $100 \mathrm{~mL}$ ) were added to the beaker to make the background ionic strength of all solution kept constant. The potassium ion sensing electrode (Qualiprobe QSE 314, EDT instruments Waldershare Park, Dover, UK) and its reference electrode (Qualiprobe double junction reference electrode E 8092 EDT instruments) were placed into the cell suspension. The potential difference $(\mathrm{mV})$ derived by the electrodes was measured using a Whatman Maidstone, UK. E. coli and $S$. dysenteriae cells were treated with various concentrations of the fractions relative to the MIC. The potassium ions leaked out from the cells of the organisms were measured at time interval over a period of $2 \mathrm{~h}$ as a potential difference in $\mathrm{mV}$. These values were later converted to concentrations of potassium ions by reference to a conversion graph which had been constructed using potassium chloride standard solutions. The concentrations of potassium ions released were plotted against time. 


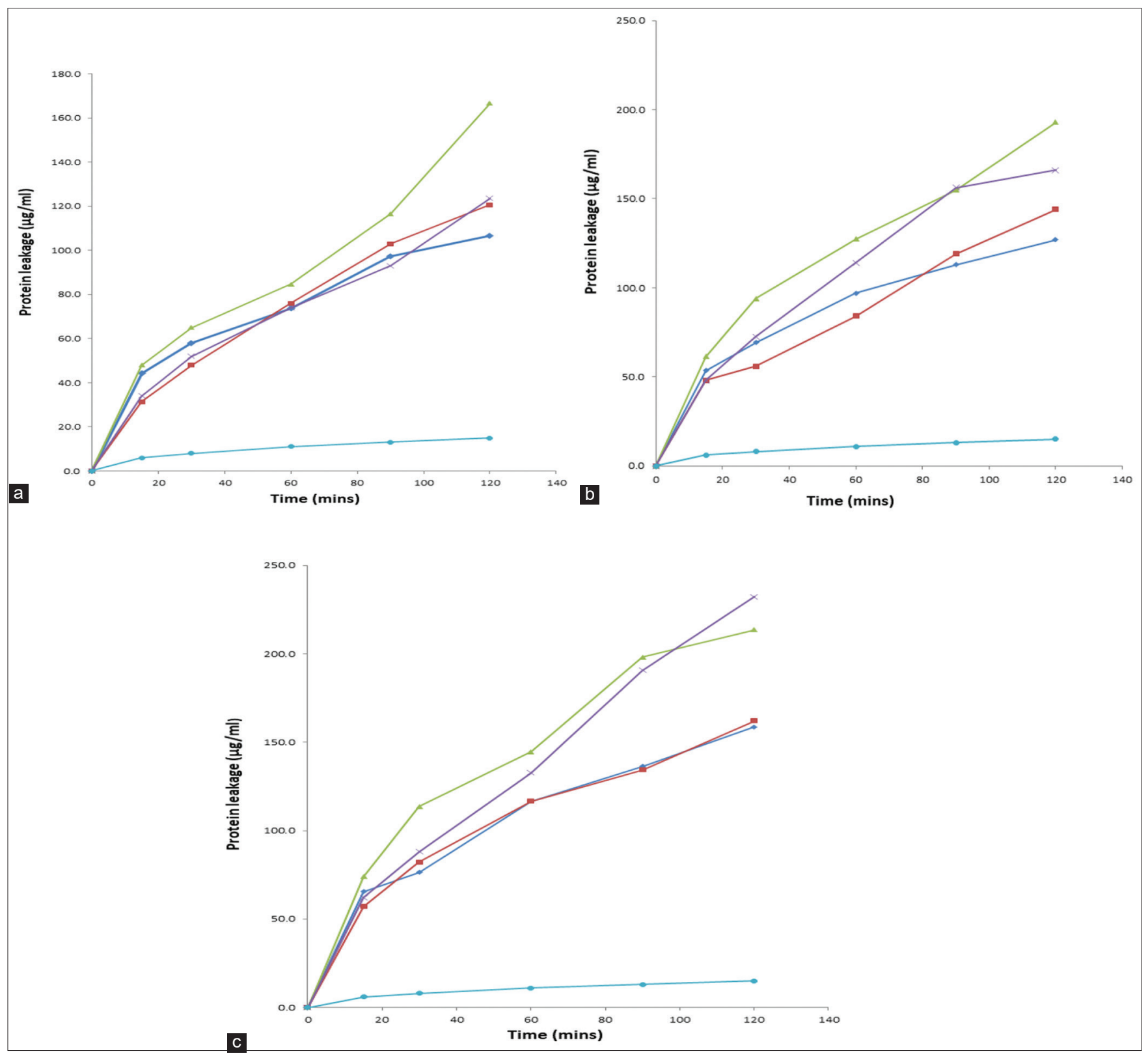

Fig. 3: (a) The effect of n-hexane fraction $(-\longrightarrow)$, chloroform fraction $(-\longrightarrow)$, ethyl acetate fraction $\left(-\begin{array}{l}- \\ -\end{array}\right.$ $(-)$, and control (-) on protein leakage from Escherichia coli at $\times 1$ minimum inhibitory concentrations (MIC). Each point represents the quantity of protein leaked $(\mu \mathrm{g} / \mathrm{ml})$ from the bacterial cells at a particular time interval in the presence of the fractions. (b) The effect of n-hexane fraction (- - ), chloroform fraction (- - ), ethyl acetate fraction (- - ), butanol fraction (-), and control (-) on protein leakage from $E$. coli at $\times 2$ MIC. Each point represents the quantity of protein leaked $(\mu \mathrm{g} / \mathrm{ml})$ from the bacterial cells at a particular time interval in the presence of the fractions. (c) The effect of $n$-hexane fraction $(-)$, chloroform fraction $(--)$, ethyl acetate fraction $(--)$, butanol fraction $(-)$, and control $(-\longrightarrow$ ) on protein leakage from E. coli at $\times 3$ MIC. Each point represents the quantity of protein leaked $(\mu \mathrm{g} / \mathrm{ml})$ from the bacterial cells at a particular time interval in the presence of the fractions

\section{Statistics and data processing}

The experiments were carried out in triplicates. Data were analyzed by a $4 \times 4$ Latin square designated with the statistical program using the GLM model (Statistical Analysis Systems Institute, Cary NC, USA, 2001). Results were contrasted with negative and a positive control. The mean of the values was compared using independent $t$-test of significance $(p<0.05)$

\section{RESULTS}

Exactly $130.5 \mathrm{~g}$ of crude extract was obtained from $1500 \mathrm{~g}$ of powdered stem bark of P. guajava. This gave $8.7 \%$ yield of the total weight of powdered sample used and the extract was dark brown in color. Four fractions were obtained from the crude extract and these include $\mathrm{n}$-hexane, chloroform, ethyl-acetate, and butanolic fractions. The crude extract along with the four fractions exhibited appreciable antimicrobial activities against all the 72 bacterial strains used for this study. The crude extract exhibited antimicrobial activity at a final concentration of $25 \mathrm{mg} / \mathrm{mL}$ while all the four fractions exhibited antimicrobial activities at a final concentration of $10 \mathrm{mg} / \mathrm{mL}$. On the other hand, streptomycin at a concentration of $1 \mathrm{mg} / \mathrm{mL}$ inhibited the growth of 64 test organisms while ampicillin at the same concentration with streptomycin inhibited the growth of 22 organisms only (Tables 1 and 2). Overall, the crude extract along with the four fractions compared favorably with the two 


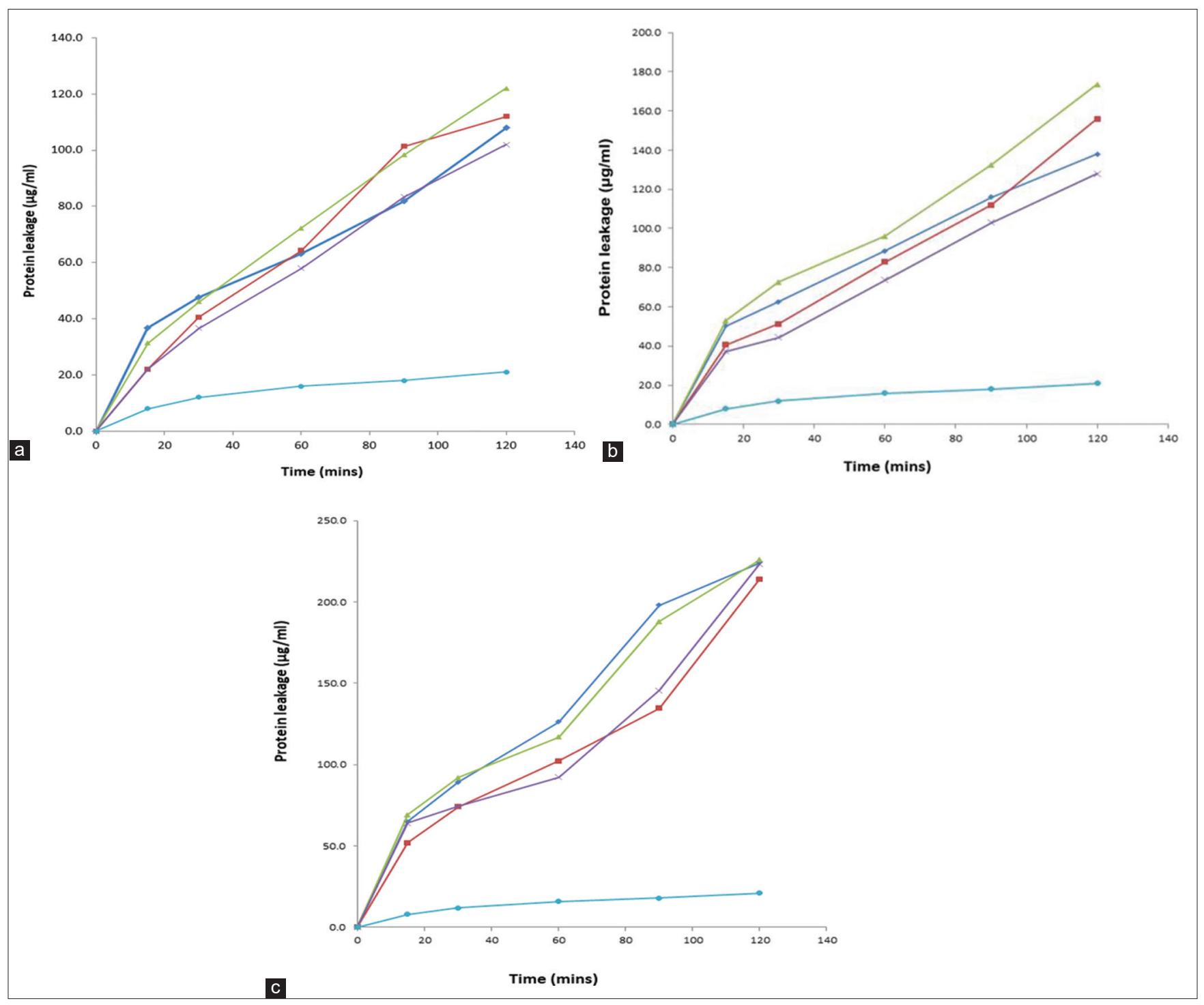

Fig. 4: (a) The effect of n-hexane fraction $(-\longrightarrow)$, chloroform fraction $(-\longrightarrow)$, ethyl acetate fraction $\left(-\frac{\square}{-}\right)$, butanol fraction $(-)$, and control (-) on protein leakage from Shigella dysenteriae at $\times 1$ minimum inhibitory concentrations (MIC). Each point represents the quantity of protein leaked $(\mu \mathrm{g} / \mathrm{ml})$ from the bacterial cells at a particular time interval in the presence of the fractions. (b) The effect of n-hexane fraction (- - ), chloroform fraction (- - ), ethyl acetate fraction $(-\infty)$, butanol fraction (- - ), and control (-) on protein leakage from $S$. dysenteriae at $\times 2$ MIC. Each point represents the quantity of protein leaked $(\mu \mathrm{g} / \mathrm{ml}) \mathrm{from}$ the bacterial cells at a particular time interval in the presence of the fractions. (c) The effect of $n$-hexane fraction ( - - ) chloroform fraction $(--)$, ethyl acetate fraction $(-)$, butanol fraction $(-)$, and control $(-)$ on protein leakage from S. dysenteriae at $\times 3$ MIC. Each point represents the quantity of protein leaked $(\mu \mathrm{g} / \mathrm{ml})$ from the bacterial cells at a particular time interval in the presence of the fractions

standard antibiotics, namely, streptomycin and ampicillin used as a positive control.

The MIC and MBC of the crude extract along with those of the four fractions were also assessed. The crude extract and the fractions exhibited varying degrees of MIC and MBC against test organisms used for this study, as indicated in Tables 3 and 4. The MIC exhibited by the crude extract against both $E$. coli and S. dysenteriae ranged between $1.56 \mathrm{mg} / \mathrm{mL}$ and $12.5 \mathrm{mg} / \mathrm{mL}$. On the other hand, the range exhibited by the fractions against susceptible organisms ranged between $0.31 \mathrm{mg} / \mathrm{mL}$ and $5.0 \mathrm{mg} / \mathrm{mL}$

The MBC exhibited by the crude extract against the bacterial strains followed the same trend with those observed for the MIC. The MBC ranged between $3.13 \mathrm{mg} / \mathrm{mL}$ and $12.5 \mathrm{mg} / \mathrm{mL}$. On the other hand, the MBC observed for the fractions against $E$. coli and $S$. dysenteriae ranged between $0.63 \mathrm{mg} / \mathrm{mL}$ and $5.0 \mathrm{mg} / \mathrm{mL}$.
The phytochemical compounds that were responsible for the biological activities of the stem bark extract of P. guajava were also investigated as shown in Table 5. The extract revealed the presence of saponins, alkaloids, flavonoids, tannins, steroids, cardiac glycosides, and reducing sugars.

The biocidal potentials of the fractions obtained from the stem bark extract of $P$. guajava were also investigated. This was assessed through the killing rate effects of the test cells protein and potassium ions leakages from the test cells. Fig. 1a-c shows the extent and killing rate of $E$. coli when subjected to the effect of the four fractions, namely, $\mathrm{n}$-hexane, chloroform, ethyl acetate, and butanol fractions at different concentrations relative to the MIC of these fractions. The percentage of the cells of $E$. coli killed by n-hexane and chloroform fractions in $15 \mathrm{~min}$ at $\times 1$ MIC was $14.9 \%$ and $17.2 \%$, respectively. The killing rate exhibited by ethyl acetate and butanol fractions at the same time interval of 15 min was $35.3 \%$. The rate at which these cells were killed increases 


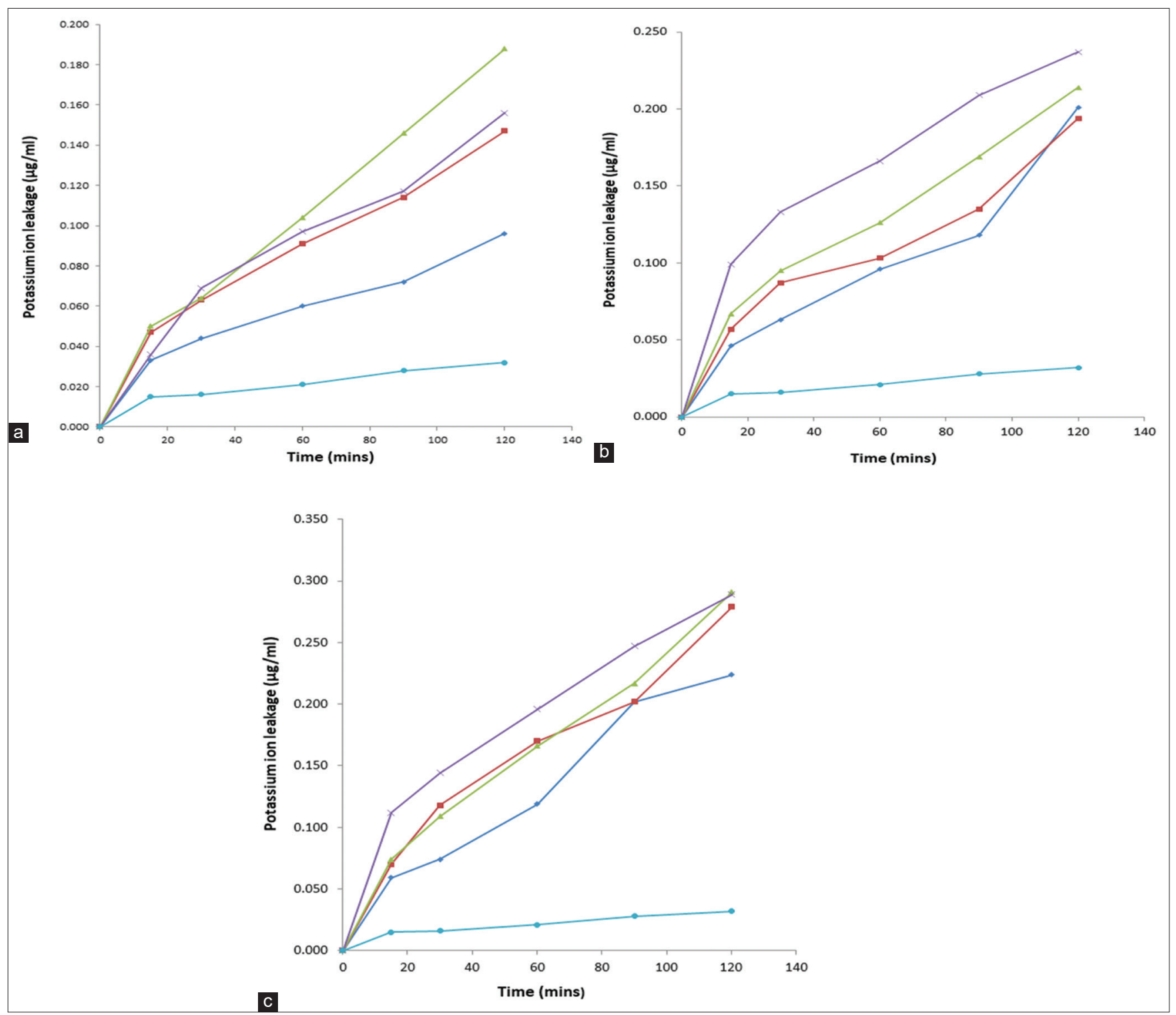

Fig. 5: (a) The effect of n-hexane fraction ( - ), chloroform fraction $(--)$, ethyl acetate fraction $\left(-\frac{1}{-}\right)$, butanol fraction ), and control (-) on potassium ion leakage from Escherichia coli at $\times 1$ minimum inhibitory concentrations (MIC). Each point represents the quantity of potassium leaked $(\mu \mathrm{g} / \mathrm{ml})$ from the bacterial cells at a particular time interval in the presence of the fractions. (b) The effect of $n$-hexane fraction $(-\infty)$, chloroform fraction $(--)$, ethyl acetate fraction $(-$ ), butanol fraction $(-)$, and control (-) on potassium ion leakage from $E$. coli at $\times 2$ MIC. Each point represents the quantity of potassium leaked $(\mu \mathrm{g} / \mathrm{ml})$ from the bacterial cells at a particular time interval in the presence of the fractions. (c) The effect of $\mathrm{n}$-hexane fraction $(-$ chloroform fraction $(--)$ ), ethyl acetate fraction $(-\infty)$, butanol fraction $(-)$ ), and control $(-\infty)$ on potassium ion leakage from $E$. coli at $\times 3$ MIC. Each point represents the quantity of potassium leaked $(\mu \mathrm{g} / \mathrm{ml})$ from the bacterial cells at a particular time interval in the presence of the fractions

with a contact time of these cells with the fractions. Finally, when the contact time was increased to $120 \mathrm{~min}$, the percentage of cells killed by butanol, n-hexane, ethyl acetate, and chloroform fractions at $\times 1$ MIC increased to $81.8 \%, 84.9 \%, 86.4 \%$, and $89.1 \%$, respectively. The same trend of reactions was observed when the concentrations of the fractions increased to $\times 2$ MIC and $\times 3$ MIC.

As shown in Fig. 2a-c, results obtained for killing rate on S. dysenteriae cells when subjected to $\mathrm{n}$-hexane, chloroform, ethyl-acetate, and butanol followed the same trend as exhibited in the tests carried out on E. coil.

The biocidal effect of the four fractions, namely, n-hexane, chloroform, ethyl-acetate, and butanol fraction was also investigated by assaying for leakage of protein from the protoplasm of the test organisms, that is, E. coli and S. dysenteriae. The protein leakage from E. coli cells due to the effect of n-hexane, chloroform, ethyl acetate, and butanol fractions at different concentrations relative to the MIC at $\times 1$ MIC, $\times 2$ MIC, and $\times 3$ MIC is shown in Fig. 3a-c. The leakage effect on E. coli cells at $\times 1$ MIC in 15 min contact time interval by n-hexane, chloroform, ethyl acetate, and butanol fractions was $44.3 \mu \mathrm{g} / \mathrm{mL}, 31.3 \mu \mathrm{g} / \mathrm{mL}$, $48.0 \mu / \mathrm{mL}$, and $34.0 \mu \mathrm{g} / \mathrm{mL}$, respectively. The contact time of the cells with the fractions was later increased to $30 \mathrm{~min}, 60 \mathrm{~min}, 90 \mathrm{~min}$, and finally $120 \mathrm{~min}$. When the contact time of the cell with the fractions at $1 \times$ MIC concentration reached $120 \mathrm{~min}$, the percentage of protein leaked out of the cells increased. The percentage increase for $n$-hexane, chloroform, ethyl acetate, and butanol fractions was $127.0 \mu \mathrm{g} / \mathrm{mL}$, $144.0 \mu \mathrm{g} / \mathrm{mL}, 193.5 \mu \mathrm{g} / \mathrm{mL}$, and $166.0 \mu \mathrm{g} / \mathrm{mL}$, respectively. The same trend of reactions was observed when the concentrations of the fractions increased to $\times 2$ MIC and $\times 3$ MIC. 


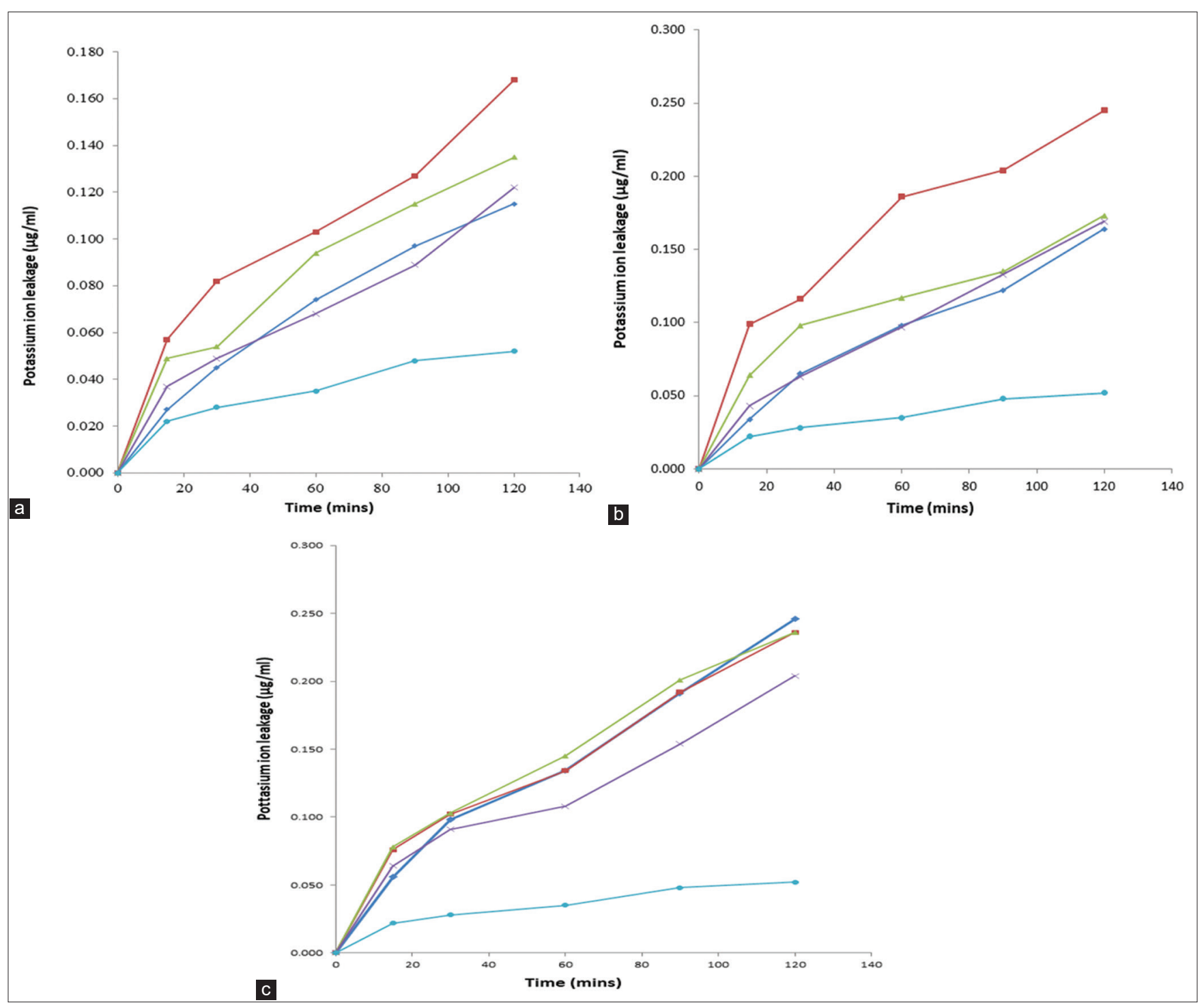

Fig. 6: (a) The effect of n-hexane fraction ( - ), chloroform fraction $(--)$, ethyl acetate fraction $(-4)$, butanol fraction $(-$, and control (-) on potassium ion leakage from Shigella dysenteriae at $\times 1$ minimum inhibitory concentrations (MIC). Each point represents the quantity of potassium leaked $(\mu \mathrm{g} / \mathrm{ml})$ from the bacterial cells at a particular time interval in the presence of the fractions. (b) The effect of $n$-hexane fraction $(-)$, chloroform fraction $(--)$, ethyl acetate fraction $(-$ ), butanol fraction $(-$ ), and control (-) on potassium ion leakage from $S$. dysenteriae at $\times 2$ MIC. Each point represents the quantity of potassium leaked $(\mu \mathrm{g} / \mathrm{ml})$ from the bacterial cells at a particular time interval in the presence of the fractions. (c) The effect of n-hexane fraction $(-)$, chloroform fraction $(-\longrightarrow)$, ethyl acetate fraction $(--)$, butanol fraction $(\longrightarrow)$, and control $(-)$ on potassium ion leakage from S. dysenteriae at $\times 3$ MIC. Each point represents the quantity of potassium leaked $(\mu \mathrm{g} / \mathrm{ml})$ from the bacterial cells at a particular time interval in the presence of the fractions

S. dysenteriae cells were also subjected to the effect of protein leakage from their cells by n-hexane, chloroform, ethyl acetate, and butanol fraction. The concentrations of the protein leaked out of the test cells continue to rise as the concentration of the fractions increases. Fig. 4a-c represents the leakages from $S$. dysenteriae through the action of the four fractions.

Finally, the cidal effects of the four fractions on potassium ions leakage from the test cells were investigated. The effect of n-hexane, chloroform, ethyl acetate, and butanol fractions on potassium ion leakage from $E$. coli cells at $\times 1 \mathrm{MIC}, \times 2 \mathrm{MIC}$, and $\times 3$ MIC is shown in Fig. $5 \mathrm{a}-\mathrm{c}$. The effect of the four fractions on potassium ions leakages from $E$. coli cells at a concentration of $\times 1$ MIC at 15 min contact time is shown in Fig. $5 \mathrm{a}$. The $\mathrm{n}$-hexane, chloroform, ethyl acetate, and butanol fractions leaked out $0.033 \mu \mathrm{g} / \mathrm{mL}$, respectively, after $15 \mathrm{~min}$ of contact time with E. coli cells. The leakage of potassium ions continued to increase with an increase in a contact time of the fraction with the bacterial cells. When the contact time reached $120 \mathrm{~min}$ at $\times 1$ MIC concentration, the quantity of potassium ions leaked out of the test cells rose up to $0.096 \mu \mathrm{g} / \mathrm{mL}, 0.147 \mu \mathrm{g} / \mathrm{mL}, 0.188 \mu \mathrm{g} / \mathrm{mL}$, and $0.156 \mu \mathrm{g} / \mathrm{mL}$ when treated with $\mathrm{n}$-hexane, chloroform, ethyl acetate, and butanol fractions, respectively. The same trend of reactions was observed for $\times 2$ MIC and $\times 3$ MIC concentrations of the fractions.

S. dysenteriae cells were also subjected to the effects of the fractions for potassium ions leakage. Appreciable quantities of potassium ion were also leaked out of the cells and follow the same trend with those observed for the E. coli cells. Fig. 6a-c shows the effects of the four fractions on $S$. dysenteriae cells. The higher the concentrations of the extract and contact time, the more potassium ions got leaked out of this bacterial cells as observed for $E$. coli. 


\section{DISCUSSION}

The biocidal effects of $P$. guajava stem bark extract were investigated against a panel of $E$. coli and $S$. dysenteriae that are causative agent of diarrhea and dysentery [2]. Four fractions were obtained from the crude extract of $P$. guajava stem bark. The crude extract along with the four fractions exhibited broad spectrum activities on all the 72 bacterial strains used for this study. In contrast to the positive control used, that is, streptomycin and ampicillin, streptomycin showed an almost similar trend of activity with both the crude extract and the fractions. On the other hand, ampicillin showed less activity in comparison to the crude extract and all the four fractions. Thus, the crude extract and the four fractions exhibited appreciable antimicrobial activities against $E$. coli and $S$. dysenteriae. Hence, the stem bark extract of P. guajava could serve as a pointer towards the development of drugs of natural origin for the treatment of diarrhea and dysentery. Our findings thus support the usefulness of $P$. guajava in folklore remedy for the treatment of infections caused by microorganisms. The MIC and MBC of the crude extract and those of the fractions were investigated. The crude extract revealed the lowest MIC of $1.56 \mathrm{mg} / \mathrm{mL}$ and MBC of $3.13 \mathrm{mg} / \mathrm{mL}$. On the other hand, the lowest MIC exhibited by the fractions was $0.31 \mathrm{mg} / \mathrm{mL}$ and the lowest MBC was $0.63 \mathrm{mg} / \mathrm{mL}$. Plant extract with very low MIC and MBC is known to possess high antimicrobial potency [21]. According to Shanmughapriya et al. [22], plants extract with MIC index which is equal or $<2 \mathrm{mg} / \mathrm{mL}$ is considered as bactericidal while those above $2 \mathrm{mg} / \mathrm{mL}$ but $<16 \mathrm{mg} / \mathrm{mL}$ are said to be bacteriostatic. This observation showed that $P$. guajava stem bark extract is bactericidal in action. As a matter of fact, such a plant could be a good source of antimicrobial drug of natural origin that can be used to combat diarrhea and dysentery that are killer diseases especially among the children in underdeveloped countries. Some phytochemical compounds which include tannins, flavonoids, alkaloids, cardiac glycosides, saponins, and reducing sugars were detected in P. guajava stem bark extract. Such phytochemicals are known to contribute to the biological activities of medicinal plants [16]. This was revealed in the cidal effect of the studied extract of $P$. guajava on bacterial strains used for this study. The cidal effects on cells of E. coli and $S$. dysenteriae which were observed through the killing rate of the test cells along with protoplasmic leakage of proteins and potassium ions might be enhanced by phytochemicals present in this plant extract. These phytochemicals usually form a complex with extracellular bacterial cell walls causing lysis of the cell wall and disruption of cell membranes of the organisms [23]. All the fractions used for the investigations of the killing rate of $E$. coli and $S$. dysenteriae cells achieved $100 \%$ killing of these cells at low concentrations within the shortest period of time. This ability of P. guajava stem bark extract to kill these organisms within the shortest period of time indicates a bactericidal effect. This observation supported the findings of Pankey and Sabath [24]. The killing of these test bacterial isolates could be attributed to damage caused to the cytoplasmic membrane of these organisms. Damage to the cytoplasmic membrane will lead to the leakage of protoplasmic inclusion. Hence, leakage of protein and potassium ions from the protoplasms of E. coli and S. dysenteriae used for this study led to the death of these organisms. Leakage of potassium ions from protoplasms of bacteria may lead to a serious consequence on such organisms and hence the death of such an organism. Potassium is responsible for the activation of intracellular enzymes and the maintenance of a constant internal $\mathrm{pH}$ and membrane potential [25]. Potassium ions transport a critical determinant of growth and survival through its role in regulating cytoplasmic $\mathrm{pH}[26,27]$. Leakage of such important ions from bacterial protoplasm will have an adverse effect on such organisms and lead to their death. All these evidences contributed to the death of the test bacterial isolates, that is, E. coli and S. dysenteriae when subjected to the effects of $P$. guajava stem bark extracts.

\section{CONCLUSION}

P. guajava stem bark extracts exhibited bactericidal activities against a panel of organisms associated with diarrhea and dysentery. This showed a significant therapeutic potential of this plant for the treatment of dysentery and diarrhea in addition to combating infections caused by other microorganisms. This observation supported the usefulness of $P$ guajava in folklore remedies for the management of infections caused by pathogens. The ability of this plant extract to kill test bacteria used for this study at low concentration and minimal contact time has established the potential of P. guajava as a template for future drugs of natural origin. Such a drug could go a long way in health-care delivery to combat infections caused by pathogens.

\section{ACKNOWLEDGMENT}

The authors acknowledge the Department of Microbiology and Parasitology, Obafemi Awolowo University, Ile-Ife, Nigeria, for the provision of bacterial isolates used for this study. We also acknowledge Cape Peninsula University of Technology for their financial support and provision of space for the work.

\section{AUTHORS' CONTRIBUTIONS}

DAA conceptualized the study, ORA collected, and preparation of the isolates and plant materials used. ORA, MOA, and KAA carried out the microbiological assays. The manuscript was drafted by DAA, prove read, and approved by all authors.

\section{CONFLICTS OF INTEREST}

The authors declare that they have no conflicts of interest.

\section{REFERENCES}

1. Nwabunike IA, Okoli CO, Ezeugwu P, Ezike AC, Onyeto CA, Mbaoji FN, et al. Antidiarrheal potentials of Schwenckia americana L. (Solanaceae): A comparative study of the aerial part and root extracts. Int J Pharm Pharm Sci 2008;10:195-201.

2. Pelczar MJ, Chan EC, Krieg NR. Microbiology. $5^{\text {th }}$ ed. New Delhi: Tata Mc Graw-Hill Publication Company Ltd.; 2006.

3. Alayande KA, Pohl CH, Ashafa AO. In vitro assessment of Euclea crispa (Thunb.) leaf extracts against Campylobacter spp. and Escherichia colicommon diarrhoeal agents. Asian J Appl Sci 2018;6:158-65.

4. Atik N, Tarawifa S, Avriyanti E, Rahmadi AR, Hilmanto D. Psidium Guajava L. Extract increases platelet count through enhancement of stem cell factor expression in thrombocytopenic mice model. Int $\mathrm{J}$ Pharm Pharm Sci 2018;10:23-6.

5. Keay RW. In: Keay RW, Onochie CF, Stanfield DP, editors. Trees of Nigeria. A Revised Version of Nigerian Trees (1960, 1964). Oxford: Clarendon Press; 1989

6. Hassimotto NM, Genovese MI, Lajolo FM. Antioxidant activity of dietary fruits, vegetables, and commercial frozen fruit pulps. J Agric Food Chem 2005;53:2928-35.

7. Haida KS, Baron A, Haida K. Phenolic compounds and antioxidant activity of two varieties of guava and rue. Rev Bras Cienc Saude 2011;28:11-9.

8. Barbalho SM, Farinazzi-Machado FM, De Alvares Goulart R, Brunnati AC, Otoboni AM, Nicolau CC. Psidium guajava (guava): A plant of multi-purpose medicinal applicatiins. Med Aromat Plants 2012;1:104

9. Ryu NH, Park KR, Kim SM, Yun HM, Nam D, Lee SG, et al. A hexane fraction of guava leaves (Psidium guajava L.) induces anticancer activity by suppressing AKT/mammalian target of rapamycin/ ribosomal p70 S6 kinase in human prostate cancer cells. J Med Food 2012;15:231-41.

10. Pelegrini PB, Murad AM, Silva LP, Dos Santos RC, Costa FT, Tagliari PD, et al. Identification of a novel storage glycine-rich peptide from guava (Psidium guajava) seeds with activity against gramnegative Bacteria. Peptides 2008;29:1271-9.

11. Bontempo P, Doto A, Miceli M, Mita L, Benedetti R, Nebbioso A, et al. Psidium guajava L. Anti-neoplastic effects: Induction of apoptosis and cell differentiation. Cell Prolif 2012;45:22-31.

12. Akinpelu DA, Onakoya TM. Antimicrobial activities of medicinal plants used in folklore remedies in South-western Nigeria. Afr J Biotechnol 2006;5:1078-81.

13. Begum S, Hassan SI, Siddiqui BS, Shaheen F, Ghayur MN, Gilani AH. Triterpenoids from the leaves of Psidium guajava. Phytochemistry 2002;61:399-403.

14. Han EH, Hwang YP, Choi JH, Yang JH, Seo JK, Chung YC, et al. Psidium guajava extract inhibits thymus and activation-regulated 
chemokine (TARC/CCL17) production in human keratinocytes by inducing heme oxygenase-1 and blocking NF- $\mathrm{\kappa B}$ and STAT1 activation. Environ Toxicol Pharmacol 2011;32:136-45.

15. Livingston Raja NR, Sundar K. Psidium guajava Linn confers gastro protective effects on rats. Eur Rev Med Pharmacol Sci 2012;16:151-6.

16. Trease GE, Evans WC. Textbook of Pharmacognosy. $15^{\text {th }}$ ed. London: Saunders Publishers; 2002.

17. Harborne JB. Phytochemical Methods-a Guide to Modern Techniques of Plant Analysis. London: Chapman and Hall; 1998. p. 60-6.

18. Akinpelu DA, Odewade JO, Aiyegoro OA, Ashafa AO, Akinpelu OF, Agunbiade MO. Biocidal effects of stem bark extract of Chrysophyllum albidum G. Don on vancomycin-resistant Staphylococcus aureus. BMC Complement Altern Med 2016;16:105.

19. Akinpelu DA, Kolawole DO. Phytochemical and antimicrobial activity of leaf extract of Piliostigma thonningii (Schumi). Sci Focus 2004; 7:64-70

20. Bradford MM. A rapid and sensitive method for the quantitation of microgram quantities of protein utilizing the principle of protein-dye binding. Anal Biochem 1976;72:248-54.

21. Saha A, Ahmed M. The analgesic and anti-inflammatory activities of the extract of Albizia lebbeck in animal model. Pak J Pharm Sci 2009;22:74-7

22. Shanmughapriya SA, Manilal A, Sujith S, Selvin J, Kiran GS, Natarajaseenivasan K. Antimicrobial activity of seaweeds extracts multi-resistant pathogens. Ann Microbiol 2008;58:535-41.

23. Stojković DS, Zivković J, Soković M, Glamočlija J, Ferreira IC, Janković T, et al. Antibacterial activity of Veronica montana L. extract and of protocatechuic acid incorporated in a food system. Food Chem Toxicol 2013;55:209-13.

24. Pankey GA, Sabath LD. Clinical relevance of bacteriostatic versus bactericidal mechanisms of action in the treatment of gram-positive bacterial infections. Clin Infect Dis 2004;38:864-70.

25. Booth IR. Regulation of cytoplasmic pH in Bacteria. Microbiol Rev 1985;49:359-78

26. Epstein W. Osmoregulation by potassium transport in Escherichia coli. FEMS Microbiol Rev 1986;39:73-80

27. Cao M, Wang T, Ye R, Helmann JD. Antibiotics that inhibit cell wall biosynthesis induce expression of the Bacillus subtilis sigma(W) and sigma(M) regulons. Mol Microbiol 2002;45:1267-76. 